\title{
ENSAYOS
}




\section{LA BUENA ENSEÑANZA Y LA FORMACIÓN DE CIUDADANÍA DEMOCRÁTICA EN AMÉRICA LATINA *}

\section{Resumen}

La educación en América Latina transcurre entre las enormes esperanzas que en sus maestras tienen los estudiantes y lo poco que estos mismos estudiantes aprenden en la escuela. Revertir esta situación requerirá desarrollar las competencias pedagógicas de los docentes, pues ahí está la clave para permitir a las niñas y a los niños aprender en profundidad contenidos significativos que les permitan cambiar sus opciones en la vida, concentrándose particularmente en aquellos estudiantes cuyos padres tienen los más bajos niveles educativos. Centrarse en la buena enseñanza requiere alinear los objetivos del currículo con los propósitos de la educación y crear las condiciones para apoyar a las maestras y a estudiantes en el logro de estos objetivos. Crear estas condiciones a su vez requerirá utilizar el mejor conocimiento disponible sobre cómo promover el aprendizaje, invertir en generar conocimiento específico en contextos particulares y difundir este conocimiento de forma que él mismo mejore la comprensión pública sobre cómo promover el éxito académico de los estudiantes y contribuir a desarrollar una nueva cultura educativa en la región.

\section{Palabras clave}

Calidad de la enseñanza, finalidades de la educación, democracia, ciudadanía, América Latina.

\section{Summary}

Education in Latin America elapses between the enormous hopes that students have in their teachers and the little that these same students learn at school. Reverting this situation will require to develop the pedagogic competitions of teachers, because this is the clue to allow girls and boys to learn in depth the meaningful contents which allow them to change their options in life, concentrating particularly on those students whose parents have the lowest educational levels. Focusing in good teaching requires to align the objectives of the curriculum with the purposes of education and to create the conditions to support teachers and students in the achievement of these objectives. In turn creating these conditions will require the use of the best available knowledge on how to promote learning, how to invest to generate specific knowledge in particular contexts and how to spread this knowledge so that it improves public understanding on how to promote students' academic success and how to contribute to develop a new educational culture in the region.

\section{Key words}

Quality of the teaching, purposes of the education, democracy, citizenship, Latin America.

\footnotetext{
* Artículo recibido el 14 de octubre de 2003 y arbitrado el 17 de octubre de 2003. 


\section{LA BUENA ENSEÑANZA Y LA FORMACIÓN DE CIUDADANÍA DEMOCRÁTICA EN AMÉRICA LATINA *}

FERNANDO REIMERS ${ }^{27}$

Una de las funciones más importantes de la escuela en una sociedad democrática es la de desarrollar competencias en todos los ciudadanos para ser libres, para valorar la diversidad, para vivir en paz con otras personas y para participar competentemente en distintas esferas de acción social. Las competencias para la participación democrática incluyen destrezas cívicas que permitan pensar sobre las formas de balancear los intereses privados con los públicos; comprender la manera en que las acciones de los gobernantes electos, en su administración de los recursos de los contribuyentes y en la regulación de lo público, avanzan u obstaculizan el interés común y la libertad; ejercer el derecho al voto de una forma razonada; comunicarse con funcionarios públicos electos o nombrados para exigir transparencia y efectividad en la administración de los recursos de los contribuyentes; contribuir en campañas políticas, asociarse con otros a nivel comunitario para avanzar los intereses de la comunidad y protestar cuando sea necesario. Estas competencias para la participación democrática requieren de habilidades y disposiciones que permitan pensar por cuenta propia, comunicarse adecuadamente, tener acceso y utilizar el conocimiento disponible sobre diversos temas, aprender continuamente, trabajar con los demás y comprender la importancia y los mecanismos de dicha participación y las diferencias que distinguen a las sociedades cerradas y totalitarias de las sociedades abiertas. En el caso específico de Colombia, creo que las competencias fundamentales para reconstruir la paz incluyen el desarrollo de habilidades interpersonales e intrapersonales que permitan valorar la dignidad fundamental de cada persona, resolver diferencias y lograr acuerdos de forma pacífica, y en los casos en que las personas hayan sido directamente afectadas por violencia de diverso tipo, liberar a las personas de las emociones que llevan a actuar agresivamente y ayudarles a perdonar y reconciliarse con los demás.

Estas competencias pueden adquirirse y perfeccionarse en distintas instituciones, en las familias, en el trabajo, en instituciones religiosas y en instituciones educativas. En ciertas familias, por ejemplo, los niños aprenden observando a los adultos a su alrededor cómo participar políticamente, cómo contactar a funcionarios electos para exigir sus derechos, o como comunicar las ideas propias y organizar a otros para avanzar propósitos comunes. En ciertas ocupaciones, igualmente, es posible desarrollar estas competencias. Por ejemplo, la docencia es una profesión donde es posible perfeccionar la capacidad de comunicar ideas a grupos, de organizar grupos y de negociar intereses diversos. La práctica con los estudiantes permite a los profesores desarrollar habilidades $y$ disposiciones que son fácilmente transferibles a la esfera política. Es debido a estas competencias que permiten participar efectivamente que en muchos países los educadores son un grupo políticamente importante, más allá del número de votos que ellos representan en las elecciones. Entre todas estas instituciones es la escuela la que

\footnotetext{
*Artículo recibido el 14 de octubre de 2003 y arbitrado el 17 de octubre de 2003.

${ }^{27}$ Profesor Universidad de Harvard. reimerfe@gse.harvard.edu

Este artículo se basa en una presentación del autor en el Congreso Latinoamericano de Reformas Educativas para el siglo XXI auspiciada por REDUC y Foro Educativo y realizada en Lima, Perú en octubre de 2003 y en otra realizada ante la Alianza para la Equidad y Competitividad Regional por la Educación auspiciada por el Banco Mundial y el Programa de Naciones Unidas para el Desarrollo, realizada en Bogotá en Abril de 2003, y toma libremente planteamientos del artículo del mismo autor: "La Buena enseñanza y el éxito escolar de los estudiantes en América Latina" Revista de la Organización de Estados Iberoamericanos, enero-abril 2003, número 31, pp. 17-48.
} 
puede distribuir competencias para participar efectivamente en una democracia de forma más equitativa.

La pedagogía, la forma en que los profesores enseñan, y la cultura escolar, la forma en que las escuelas están organizadas, es central en el desarrollo de estas competencias y disposiciones. En palabras de John Dewey, los maestros enseñan en la manera en que enseñan, por lo tanto asegurar que todos los ciudadanos tengan las competencias necesarias para pensar por cuenta propia, para valorar la libertad de hacerlo y la de que otros lo hagan, para comunicarse adecuadamente y trabajar con otros, requiere esfuerzos decididos y efectivos de apoyo a la tarea de los maestros. Esquemáticamente, esta tesis sostiene que para formar ciudadanos: 1) hay que educar a todos con altos niveles de calidad y 2) hay que hacerlo de forma que permita desarrollar competencias para la participación democrática. Lograr esto remite a fortalecer las competencias pedagógicas de los maestros y el clima social y emocional en las escuelas. En síntesis, construir una cultura democrática requiere construir una cultura educativa que permita formar ciudadanos democráticos. Este objetivo no se logra con eslóganes ni con programas estancos sino con trabajo serio y dedicado para que los maestros orienten su trabajo, cada día, al desarrollo de estas competencias.

Insistir en estos propósitos es necesario en momentos en que los críticamente bajos resultados de los sistemas educativos de América Latina podrían llevar a un pensamiento cortoplacista, a confundir los medios con los fines. Dado que una proporción muy alta de los estudiantes no pueden leer con comprensión, y que muchos de ellos no alcanzan a completar la secundaria, este pensamiento de emergencia podría llevar a entender que el fin es hacer que los estudiantes puedan leer y completar la secundaria. Estos logros en sí mismos serían equivocados no por innecesarios sino por insuficientes, pues es posible producir personas letradas y con altos niveles de escolaridad que no tengan las capacidades de pensar por cuenta propia, de valorar la libertad y de ejercer ciudadanía democrática. Es posible enseñar a leer de forma autoritaria, donde se aprendan las sílabas de forma mecánica, pero no el gusto por leer ni la habilidad de utilizar la lectura para dialogar en el mundo de las ideas, es posible enseñar a resolver problemas matemáticos de forma mecánica, sin enseñar a pensar utilizando el lenguaje de las matemáticas. En el contexto de emergencia en que se encuentran buena parte de los sistemas educativos de la región, es útil mantener el énfasis en el fin de formar ciudadanos democráticos capaces, pensadores independientes y libres, con el objetivo de que los medios que se escojan para enseñar a leer, o para desarrollar habilidades matemáticas o científicas sirvan también para desarrollar el gusto por las ideas, la confianza en la propia capacidad de generarlas, la habilidad para hacerlo, la valoración de las ideas de los demás, y el conjunto de competencias intrapersonales e interpersonales a las que me referí antes y que hacen a una cultura democrática. Este énfasis en los fines es tanto más necesario en contextos culturales de largas tradiciones autoritarias.

\section{Las enormes esperanzas que tienen los estudiantes y sus familias en sus maestras}

Los jóvenes latinoamericanos y sus familias tienen enormes esperanzas en la escuela y en sus maestras. Una encuesta reciente administrada a jóvenes de 15 años en los países de la OECD y en algunos otros países, ofrece información sobre Argentina, Brasil, Chile, México y Perú, que nos permite contrastar las perspectivas de estos estudiantes latinoamericanos con las de los estudiantes en otros países del mundo. Lo primero que hay que destacar es que a los estudiantes latinoamericanos les gusta asistir a la escuela, aparentemente más que a los estudiantes en otros países en la 
OECD. Al preguntarles a los jóvenes si no les gustaba asistir a la escuela, la mayoría de los estudiantes latinoamericanos estuvieron en desacuerdo con esta afirmación, en porcentajes muy superiores a los de sus pares en los países de la OECD como se muestra en el cuadro 1. Estos resultados quizás simplemente indiquen que donde la educación es un bien escaso, acaso sea más valorada que donde la oportunidad de ir a la escuela sea tan común que deja de ser apreciada.

Cuadro 1. Porcentaje de estudiantes que indican estar de acuerdo con la afirmación 'Mi escuela es un lugar donde no quiero ir' en varios países, hacia el año 2000

$\begin{array}{lccccc} & \begin{array}{c}\text { Muy en } \\ \text { desacuerdo }\end{array} & \begin{array}{c}\text { En } \\ \text { desacuerdo }\end{array} & \begin{array}{c}\text { Muy de } \\ \text { De acuerdo }\end{array} & \begin{array}{c}\text { Acuerdo } \\ \text { No contestó }\end{array} \\ \text { Argentina } & 38 \% & 27 \% & 17 \% & 9 \% & 9 \% \\ \text { Brasil } & 35 \% & 41 \% & 15 \% & 5 \% & 4 \% \\ \text { Chile } & 49 \% & 28 \% & 14 \% & 7 \% & 2 \% \\ \text { México } & 54 \% & 33 \% & 6 \% & 3 \% & 4 \% \\ \text { Perú } & 57 \% & 25 \% & 6 \% & 4 \% & 8 \% \\ \text { Alemania } & 45 \% & 29 \% & 15 \% & 10 \% & 2 \% \\ \text { Canadá } & 24 \% & 39 \% & 24 \% & 12 \% & 1 \% \\ \text { Corea } & 31 \% & 39 \% & 21 \% & 9 \% & 0 \% \\ \text { España } & 31 \% & 37 \% & 20 \% & 10 \% & 2 \% \\ \text { Estados Unidos } & 19 \% & 38 \% & 25 \% & 11 \% & 8 \% \\ \text { Francia } & 24 \% & 35 \% & 24 \% & 13 \% & 4 \% \\ \text { Japón } & 31 \% & 41 \% & 16 \% & 8 \% & 4 \% \\ \text { OECD Promedio } & 32 \% & 37 \% & 19 \% & 10 \% & 3 \%\end{array}$

Fuente: http://pisaweb.hacer.edu/au/oecd/ (accesado 18 de septiembre de 2003)

Además de indicar que se sienten a gusto en su escuela, los estudiantes latinoamericanos presentan caracterizaciones positivas de sus profesores. Por ejemplo, al preguntarles si los maestros mostraban interés en el aprendizaje de cada estudiante, una proporción superior de estudiantes latinoamericanos indicó que efectivamente éste era el caso en cada lección que sus pares en países de la OECD como puede apreciarse en el cuadro 2.

Cuadro 2. Porcentaje de estudiantes que indican con qué frecuencia 'Los maestros muestran interés en el aprendizaje de cada estudiante'en varios países, hacia el año 2000

\section{En la}

\section{En mayoría}

País

Argentina

Brasil

Chile

México

Perú

Alemania

Canadá

Corea

España

Estados Unidos

Francia

Japón

OECD Promedio

algunas de las

Nunca lecciones lecciones

$10 \%$

$5 \%$

$4 \%$

$5 \%$

$3 \%$

$20 \%$

$7 \%$

$21 \%$

$20 \%$

$19 \%$

$21 \%$

$17 \%$

$38 \%$

$24 \%$

$24 \%$

$44 \%$

$8 \%$

$7 \%$

$10 \%$

$16 \%$

$12 \%$
$21 \%$

$25 \%$

$22 \%$

$27 \%$

$27 \%$

$22 \%$

$30 \%$

$20 \%$

$27 \%$

$24 \%$

$29 \%$

$25 \%$

$27 \%$
En cada lección

$43 \%$

$49 \%$

$54 \%$

$43 \%$

$49 \%$

$18 \%$

$39 \%$

$11 \%$

$35 \%$

$41 \%$

$26 \%$

$23 \%$

$29 \%$
No

contesto

$5 \%$

$2 \%$

$1 \%$

$4 \%$

$4 \%$

$2 \%$

$1 \%$

$1 \%$

$1 \%$

$6 \%$

$2 \%$

$7 \%$

$2 \%$ 
Fuente: http://pisaweb.hacer.edu/au/oecd/ (accesado 18 de septiembre de 2003)

Igualmente, los estudiantes latinoamericanos perciben a sus maestros como dedicados a que todos los alumnos comprendan los contenidos del currículo, como muestran las respuestas a la pregunta de con qué frecuencia los maestros siguen enseñando un contenido hasta lograr que todos los alumnos lo comprendan, que se presentan en el cuadro 3.

Cuadro 3. Porcentaje de estudiantes que indican con qué frecuencia 'Los maestros siguen enseñando hasta que todos los alumnos comprendan'en varios países, hacia el año 2000

\begin{tabular}{|c|c|c|c|c|c|}
\hline País & Nunca & $\begin{array}{l}\text { En algunas } \\
\text { lecciones }\end{array}$ & $\begin{array}{l}\text { En la mayoría de } \\
\text { las lecciones }\end{array}$ & $\begin{array}{l}\text { En cada } \\
\text { lección }\end{array}$ & $\begin{array}{c}\text { No } \\
\text { contesto }\end{array}$ \\
\hline Argentina & $7 \%$ & $24 \%$ & $22 \%$ & $41 \%$ & $5 \%$ \\
\hline Brasil & $5 \%$ & $24 \%$ & $26 \%$ & $43 \%$ & $2 \%$ \\
\hline Chile & $5 \%$ & $27 \%$ & $25 \%$ & $42 \%$ & $1 \%$ \\
\hline México & $5 \%$ & $29 \%$ & $28 \%$ & $35 \%$ & $4 \%$ \\
\hline Perú & $4 \%$ & $24 \%$ & $26 \%$ & $41 \%$ & $5 \%$ \\
\hline Alemania & $12 \%$ & $34 \%$ & $29 \%$ & $24 \%$ & $1 \%$ \\
\hline Canadá & $6 \%$ & $25 \%$ & $34 \%$ & $34 \%$ & $1 \%$ \\
\hline Corea & $18 \%$ & $40 \%$ & $25 \%$ & $15 \%$ & $1 \%$ \\
\hline España & $6 \%$ & $27 \%$ & $28 \%$ & $38 \%$ & $1 \%$ \\
\hline Estados Unidos & $7 \%$ & $24 \%$ & $27 \%$ & $36 \%$ & $6 \%$ \\
\hline Francia & $9 \%$ & $32 \%$ & $28 \%$ & $29 \%$ & $2 \%$ \\
\hline Japón & $15 \%$ & $32 \%$ & $26 \%$ & $22 \%$ & $5 \%$ \\
\hline \multicolumn{6}{|l|}{ OECD } \\
\hline Promedio & $9 \%$ & $29 \%$ & $31 \%$ & $30 \%$ & $2 \%$ \\
\hline
\end{tabular}

Cuadro 4. Porcentaje de estudiantes que indican con qué frecuencia 'Los maestros quieren que los alumnos trabajen duro'en varios países, hacia el año 2000

\begin{tabular}{|c|c|c|c|c|c|}
\hline País & Nunca & $\begin{array}{c}\text { En algunas } \\
\text { lecciones }\end{array}$ & $\begin{array}{c}\text { En la } \\
\text { mayoría de } \\
\text { las } \\
\text { lecciones }\end{array}$ & Siempre & $\begin{array}{l}\text { No } \\
\text { respondió }\end{array}$ \\
\hline Argentina & $10 \%$ & $32 \%$ & $28 \%$ & $25 \%$ & $5 \%$ \\
\hline Brasil & $4 \%$ & $26 \%$ & $34 \%$ & $34 \%$ & $2 \%$ \\
\hline Chile & $4 \%$ & $28 \%$ & $31 \%$ & $37 \%$ & $1 \%$ \\
\hline México & $11 \%$ & $35 \%$ & $27 \%$ & $23 \%$ & $4 \%$ \\
\hline Perú & $6 \%$ & $18 \%$ & $31 \%$ & $41 \%$ & $4 \%$ \\
\hline Alemania & $4 \%$ & $24 \%$ & $34 \%$ & $37 \%$ & $1 \%$ \\
\hline Canadá & $2 \%$ & $14 \%$ & $34 \%$ & $50 \%$ & $1 \%$ \\
\hline Corea & $7 \%$ & $20 \%$ & $23 \%$ & $49 \%$ & $1 \%$ \\
\hline España & $11 \%$ & $40 \%$ & $29 \%$ & $19 \%$ & $1 \%$ \\
\hline Estados Unidos & $2 \%$ & $9 \%$ & $21 \%$ & $62 \%$ & $6 \%$ \\
\hline Francia & $9 \%$ & $44 \%$ & $31 \%$ & $14 \%$ & $1 \%$ \\
\hline Japón & $5 \%$ & $16 \%$ & $29 \%$ & $44 \%$ & $5 \%$ \\
\hline
\end{tabular}


Es claro pues, que los estudiantes argentinos, brasileños, chilenos, mexicanos y peruanos tienen enormes esperanzas puestas en sus maestros y en sus escuelas y valoran positivamente lo que sus maestros hacen. No sólo los estudiantes tienen muchas esperanzas puestas en la educación; también los adultos valoran las escuelas más que otras instituciones, como se aprecia en el cuadro 5. Un estudio de opinión pública, llevado a cabo en 1998, demuestra que la institución en la que más confianza tienen los chilenos y los mexicanos son las escuelas. Así, al preguntarles cuánta confianza tenían en las escuelas, un $89 \%$ de los chilenos y un $64 \%$ de los mexicanos encuestados dijeron que mucha $^{28}$.

Cuadro 5. Confianza en instituciones nacionales

\section{Cuánta confianza tiene Usted en...}

\section{Chile}

México

\section{Mucha o Alguna Poca o ninguna Mucha o alguna Poca o ninguna}

$\begin{array}{lllll}\text { Las escuelas } & 89 \% & 10 \% & 64 \% & 35 \% \\ \text { La policía } & 61 \% & 38 \% & 33 \% & 65 \% \\ \text { El gobierno } & 51 \% & 48 \% & 30 \% & 68 \% \\ \text { La prensa } & 57 \% & 41 \% & 29 \% & 66 \% \\ \text { El congreso } & 43 \% & 51 \% & 28 \% & 61 \% \\ \text { Los partidos políticos } & 27 \% & 70 \% & 30 \% & 63 \% \\ \text { El ejército } & 53 \% & 44 \% & 45 \% & 49 \%\end{array}$

Fuente: Hewlett Foundation/MORI Internacional, 1998.

\section{Los bajos niveles de escolaridad y de aprendizaje}

A pesar de las enormes esperanzas que tienen los estudiantes en América Latina y sus padres en las maestras y en las escuelas, muchos aprenden muy poco y los pobres tienen muy pocas oportunidades de culminar la enseñanza primaria, y, en consecuencia, de proceder a los niveles de educación secundaria y universitaria.

El interesarse en el acceso de los pobres a la enseñanza secundaria y universitaria es especialmente importante en América Latina por varias razones. En primer lugar, porque América Latina se caracteriza por los enormes niveles de pobreza y de desigualdad. Son la pobreza y la desigualdad las que están en la base de las recurrentes crisis políticas y de la inestabilidad de la región. Mientras la mayoría de las poblaciones latinoamericanas

\footnotetext{
${ }^{28}$ KLESNER, Joseph, "Legacies of Authoritarianism", en Ai Camp, Rodric. Citizen views of democracy in Latin America, Pittsburgh, University of Pittsburgh Press, 2001, pp. 118-138 Cuadro 4, p. 127. 
no perciban que viven en sociedades justas, el futuro se debatirá entre el autoritarismo político de izquierdas o de derechas y el consecuente conflicto social.

El futuro de los pueblos de América Latina será más justo, pacífico y con bienestar mientras más democráticas se hagan las sociedades y mientras más empleos productivos puedan generar las economías. Las democracias y los empleos productivos requieren de personas bien educadas a altos niveles. En Estados Unidos, Robert Putnam encuentra que el buen funcionamiento de la democracia requiere de la existencia de capital social, que entre otras cosas es la capacidad que tienen las personas de confiar en los demás y de asociarse con ellos para lograr proyectos compartidos. La confianza en los demás aumenta con los años de escolaridad, pero los aumentos son mayores cuando los adolescentes alcanzan la escuela secundaria ${ }^{29}$. Se han encontrado efectos similares del acceso a niveles superiores de escolaridad en la formación de capital social en Chile, Costa Rica y México ${ }^{30}$. Obviamente, más que el simple número de años de escolaridad, lo que contribuye a desarrollar la confianza interpersonal, normas de reciprocidad, y otras competencias para ejercer ciudadanía democrática, son las experiencias que se tienen en la escuela. Entre otras cosas, la escuela permite a los estudiantes la oportunidad de expresar sus ideas, y con ello de aprender a valorar la libertad de pensar por cuenta propia y de respetar el derecho de los demás a hacer lo mismo. En la encuesta mencionada anteriormente a estudiantes de 15 años, casi la mitad de los estudiantes latinoamericanos señalan que los maestros les dan a los alumnos la oportunidad de expresar su opinión.

Cuadro 6. Porcentaje de estudiantes que indican con qué frecuencia 'Los maestros le dan a los alumnos oportunidades de expresar su opinión'en varios países, hacia el año 2000

\section{El profesor le da a los alumnos oportunidades de expresar su opinión}

En la

mayoría de

$\begin{array}{lccccc}\text { País } & \begin{array}{c}\text { Nunca } \\ \text { Argentina }\end{array} & \begin{array}{c}\text { En algunas } \\ \text { lecciones }\end{array} & \begin{array}{c}\text { las } \\ \text { lecciones }\end{array} & \begin{array}{c}\text { En cada } \\ \text { lección }\end{array} & \begin{array}{c}\text { No contestó } \\ \text { Brasil }\end{array} \\ \text { Chile } & 5 \% & 22 \% & 20 \% & 45 \% & 5 \% \\ \text { México } & 6 \% & 22 \% & 27 \% & 44 \% & 2 \% \\ \text { Perú } & 2 \% & 17 \% & 24 \% & 52 \% & 1 \% \\ \text { Alemania } & 3 \% & 17 \% & 26 \% & 49 \% & 5 \% \\ \text { Canadá } & 11 \% & 25 \% & 27 \% & 35 \% & 1 \% \\ \text { Corea } & 5 \% & 20 \% & 31 \% & 42 \% & 1 \% \\ \text { España } & 15 \% & 40 \% & 27 \% & 16 \% & 1 \% \\ \text { Estados Unidos } & 8 \% & 27 \% & 26 \% & 37 \% & 1 \% \\ \text { Francia } & 7 \% & 20 \% & 25 \% & 41 \% & 7 \% \\ \text { Japón } & 10 \% & 28 \% & 27 \% & 34 \% & 2 \% \\ \text { OECD Promedio } & 10 \% & 27 \% & 28 \% & 31 \% & 5 \% \\ & 7 \% & 24 \% & 29 \% & 38 \% & 2 \%\end{array}$

Fuente: http://pisaweb.hacer.edu/au/oecd/ (accesado 18 de septiembre de 2003)

\footnotetext{
${ }^{29}$ PUTNAM, R., "Tuning In, Tuning Out: The Strange Disappearance of Social Capital in America", en Political Science and Politics 27, no 4. December 1995, p. 667.

${ }^{30}$ POWER, T. and CLARK, M, "Does Trust Matter?, in Ai Camp, R. 2001. Citizen Views of Democracy in Latin America, University of Pittsburgh Press, p. 59.
} 
Dada la importancia de la educación para desarrollar competencias ciudadanas es claro que el progreso logrado en América Latina en aumentar la escolarización de la población ha contribuido a construir una base más amplia de ciudadanos preparados para ejercer ciudadanía. Los grupos más jóvenes de la población en todos los países latinoamericanos tienen mayores niveles de escolaridad que los grupos de más edad, y estas ganancias intergeneracionales han sido mayores entre las mujeres y en zonas rurales, como muestra el cuadro 7.

En este cuadro se comparan los años promedio de escolaridad alcanzados, entre quienes tienen entre 15 y 24 años con los correspondientes a quienes tienen entre 25 a 59 años. Es claro que la escolaridad creció más entre las mujeres y más en las zonas rurales que en las urbanas. Los niveles de escolaridad de los hombres que viven en zonas urbanas, el grupo con los más altos niveles de escolaridad entre quienes tienen de 25 a 59 años, son semejantes a los de los jóvenes en este grupo. En comparación, para las mujeres que viven en zonas urbanas, el grupo más joven tiene en promedio 0,7 años más de escolaridad. Los hombres jóvenes que viven en zonas rurales tienen 1,4 años más de escolaridad que el grupo de más edad, y las mujeres jóvenes que viven en zonas urbanas tienen 2 años más de escolaridad que las que se encuentran en el grupo de más edad.

Cuadro 7. Años promedio de escolaridad alcanzados por varios grupos de población, hacia el año 2000

$\begin{array}{lcccccccc}\text { Argentina 2000 } & 9.7 & 10.5 & & & 10.2 & 10.3 & & \\ \text { Bolivia 2000 } & 10.3 & 9.9 & 6.9 & 5.7 & 10.6 & 8.8 & 5.0 & 2.9 \\ \text { Brasil 1999 } & 7.2 & 7.9 & 4.4 & 5.4 & 6.9 & 7.1 & 3.2 & 3.4 \\ \text { Chile 2000 } & 10.6 & 10.7 & 8.7 & 9.2 & 11.0 & 10.6 & 6.7 & 6.8 \\ \text { Colombia 1999 } & 9.0 & 9.3 & 6.2 & 6.8 & 8.9 & 8.4 & 4.7 & 4.9 \\ \text { Costa Rica 2000 } & 8.4 & 8.8 & 6.8 & 7.1 & 9.1 & 9.0 & 6.4 & 6.3 \\ \text { Ecuador 2000 } & 9.7 & 10.0 & 7.0 & 7.2 & 9.9 & 9.6 & 5.7 & 5.3 \\ \text { El Salvador 2000 } & 9.1 & 9.1 & 5.7 & 5.7 & 8.9 & 7.8 & 3.7 & 2.9 \\ \text { Guatemala 1998 } & 7.6 & 7.5 & 4.1 & 3.1 & 7.2 & 5.8 & 2.4 & 1.4 \\ \text { Honduras 1999 } & 7.3 & 7.8 & 4.7 & 5.1 & 7.6 & 7.1 & 3.5 & 3.6 \\ \text { México 2000 } & 9.8 & 9.7 & 7.6 & 7.4 & 9.5 & 8.6 & 5.6 & 5.0 \\ \text { Nicaragua 1998 } & 7.2 & 7.8 & 3.8 & 4.6 & 7.4 & 6.6 & 3.2 & 3.2 \\ \text { Panamá 1999 } & 9.8 & 10.3 & 7.6 & 8.4 & 10.4 & 10.5 & 6.9 & 7.2 \\ \text { Paraguay 1999 } & 9.5 & 9.4 & 6.4 & 6.5 & 9.6 & 9.0 & 5.0 & 4.5 \\ \text { Perú 1999 } & 10.2 & 10.2 & 7.5 & 6.9 & 10.9 & 9.5 & 5.7 & 3.6 \\ \text { República } & & & & & & & & \\ \text { Dominicana 2000 } & 8.8 & 9.9 & 6.3 & 7.2 & 8.9 & 8.9 & 5.2 & 5.0 \\ \text { Uruguay 2000 } & 9.0 & 9.9 & & & 9.0 & 9.4 & & \\ \text { Venezuela 2000 } & 8.2 & 9.3 & & & 8.1 & 8.5 & & \end{array}$

Fuente: Encuestas de hogares realizadas en cada país. Datos procesados por la Comisión Económica de América Latina y el Caribe. CEPAL. Social Panorama of Latin America 2001-2002. Santiago. United Nations. Cuadros 30 y 31. Los datos de Argentina corresponden sólo al Gran Buenos Aires. Los Datos para Paraguay Urbano se refieren sólo a Asunción.

A pesar de esta importante expansión en la escolaridad de la población, alcanzada durante las ultimas décadas del siglo $X X$, los niveles educativos de la población en América Latina son aún bajos relativos a los de los países de la OECD. En Brasil, por ejemplo, el $63 \%$ de la población de 25 a 59 años ha completado apenas educación primaria o menos, con sólo un $13 \%$ más que ha logrado el primer nivel de la 
escolarización secundaria. En Chile, el $31 \%$ de la población tiene educación primaria o menos y $26 \%$ el primer nivel de educación secundaria. En México, las cifras respectivas son $50 \%$ y $21 \%$; en Perú $47 \%$ y $7 \%$, y en Uruguay $53 \%$ y $16 \%$. Estas cifras comparan con promedios para la OECD de sólo $16 \%$ con escolarización primaria o menos y de $20 \%$ con educación secundaria. En Canadá estas cifras son de $7 \%$ y $13 \%$, en Estados Unidos $5 \%$ y $8 \%$. En otras palabras, en promedio tres de cada cinco personas en los países de la OECD han alcanzado al menos el nivel superior de la educación secundaria (bachillerato), y en el caso de Canadá y Estados Unidos cuatro de cada cinco personas ha logrado este nivel, lo cual compara con una de cada cinco personas en México y Brasil, una y media de cada cinco en Uruguay y dos de cada cinco en Chile y Perú (OECD, 2001 p. 43). Detrás de estos bajos niveles de escolaridad promedio de la población latinoamericana se esconden profundas disparidades en las oportunidades educativas de distintos grupos sociales.

Como resultado de que las brechas en la oportunidad de ingresar y proseguir en la escuela aumentan a medida que los estudiantes avanzan en sus trayectorias educativas, son los hijos de los pobres quienes tienen menor probabilidad de alcanzar niveles superiores de educación. Distintos grupos étnicos tienen también profundas diferencias en la oportunidad de alcanzar niveles superiores de escolaridad. En Brasil, por ejemplo, las personas blancas de 25 a 60 años tienen, en promedio, 7 años más de escolaridad que los afrobrasileños que tienen sólo 4 años de escolaridad. En Guatemala, las personas indígenas tienen 2 años de escolaridad en promedio, en comparación con más de cinco años de escolaridad entre quienes no son indígenas. En Perú, las personas indígenas tienen menos de 6 años de escolaridad en promedio, en comparación con más de 9 años de escolaridad entre quienes no son indígenas. En Bolivia, los pueblos indígenas tienen 4 años de escolaridad, comparados con 9 años de escolaridad entre los no-indígenas ${ }^{31}$. Tan preocupante como estas brechas en los niveles educativos entre distintos grupos étnicos y raciales, es la persistencia de dichas brechas a pesar de los aumentos de escolaridad de una generación a otra. En Brasil, por ejemplo, la diferencia de escolaridad entre una persona blanca y sus pares mulatos o negros se ha mantenido durante los últimos 50 años ${ }^{32}$.

Una encuesta llevada a cabo en 1998 entre 3,396 adultos en Costa Rica y Chile y México, demuestra claras diferencias en las oportunidades de acceso a la educación de las personas blancas, morenas y mulatas, diferencias que son muy superiores en México que en Costa Rica o Chile. Así, en México, entre las personas blancas el $22 \%$ tenían entre 1 y 6 años de escolaridad, el 32\% educación secundaria y el $41 \%$ educación universitaria. Entre las personas morenas, las cifras respectivas eran $36 \%$ con educación primaria, $38 \%$ con secundaria y $24 \%$ con educación universitaria. Entre las personas indígenas el $53 \%$ tenía alguna educación primaria, el $30 \%$ secundaria y el $11 \%$ educación universitaria. Es decir, la probabilidad de tener educación universitaria era 4 veces mayor para una persona blanca que para una persona mulata y 2 veces mayor que para una persona indígena. En Costa Rica, en cambio, la probabilidad de tener educación universitaria era dos veces más alta para una persona blanca que para una persona mulata o morena; en Chile la probabilidad de tener educación universitaria era la misma para una persona blanca que para una morena y tres veces superior que para una persona mulata ${ }^{33}$.

\footnotetext{
${ }^{31}$ IDB 2001, Measuring Social Exclusion: Results from Four Countries. cited in Preal. Quedándonos atrás. Un informe del progreso educativo en América Latina. Washington, DC. Preal. p. 10.

32 HENRIQUES, R., Raça e Gênero nos Sistemas de Ensino: Os limites das políticas universalistas em educação. Brasília, UNESCO, 2002.

${ }^{33}$ Idem. Cuadro 3, p. 145.

Digitalizado por RED ACADEMICA
} 
Cuadro 8. Porcentaje de adultos por nivel más alto de educación alcanzado para distintos grupos raciales, en 1998

Color de Piel Proporción Proporción

Educación

\author{
Primaria \\ Secundaria \\ Superior
}

\section{Primaria \\ Secundaria \\ Superior}

\section{Primaria \\ Secundaria}

Superior

\section{México}

$\begin{array}{lllll}22 & 36 & 53 & 1.64 & 2.41 \\ 32 & 38 & 30 & 1.19 & 0.94 \\ 41 & 24 & 11 & 0.59 & 0.27\end{array}$

\section{Costa Rica}

$\begin{array}{lcccc}50 & 54 & 54 & 1.08 & 1.08 \\ 26 & 22 & 23 & 0.85 & 0.88 \\ 18 & 10 & 7 & 0.56 & 0.39\end{array}$

\section{Chile}

$\begin{array}{lcccc}35 & 38 & 50 & 1.09 & 1.43 \\ 38 & 38 & 40 & 1.00 & 1.05 \\ 26 & 24 & 9 & 0.92 & 0.35\end{array}$

Fuente: Basanez and Paras. Color and Democracy in Latin America, p. 145.

Dado que es el acceso a los niveles superiores de educación el que califica para los empleos más productivos y mejor remunerados, la legitimidad misma de la democracia descansa en que el acceso a los mejores empleos esté abierto a aquellos con las competencias necesarias y que las oportunidades de adquirir estas competencias necesarias estén abiertas a todos los chicos y no sólo a aquellos cuyos padres ocupen en la estructura social las posiciones de mayor privilegio o estatus. En Brasil, por ejemplo, si bien el $45 \%$ de la población se considera mulato o negro, estos dos grupos representan el $70 \%$ de quienes se encuentran bajo la línea de pobreza o pobreza critica ${ }^{34}$. La encuesta señalada anteriormente revela importantes diferencias en la percepción que distintos grupos raciales tienen de la escuela y a su vez distintas diferencias en su percepción sobre la necesidad de priorizar la igualdad. Al evaluar su confianza en las escuelas, mientras que el $50 \%$ de las personas blancas indicaron tener mucha confianza en las escuelas, solo el $41 \%$ de las personas morenas y mulatas expresaron la misma confianza $^{35}$. Probablemente relacionado en parte con estas diferencias en el acceso a servicios educativos de calidad, mientras que un mayor porcentaje de las personas morenas y mulatas $(29 \%)$ consideraba a la igualdad como el derecho político más importante, sólo un $20 \%$ de las personas blancas consideraban éste el derecho político más importante, reflejo tal vez de la diferente percepción de estos grupos de personas de cuánta igualdad existe ya para ellos en sus oportunidades.

Tanto la democracia como las economías modernas necesitan de procesos abiertos donde sean el talento y el mérito los que permitan el acceso a empleos de alta productividad. Un estudio reciente sobre la procedencia educativa de los dirigentes empresariales y políticos en Chile, revela la paradoja de que el $82 \%$ de los dirigentes empresariales y el $45 \%$ de los dirigentes políticos son egresados de escuelas privadas,

\footnotetext{
${ }^{34}$ BARROS R. P.; HENRIQUES, R. and MENDONÇA, R. (2000), "A estabilidade inaceitável: desigualdade e pobreza no Brasil.", in Henriques, R. (org), Desigualdades e Pobreza no Brasil, Río de Janeiro, IPEA.

35 BASAENZ, Miguel y PARAS, Pablo, "Color and Democracy in Latin America", en Ai Camp, Rodric., 2001,

Op. cit., pp. 139-153, cuadro 2, en p. 141.
} 
aun cuando estas escuelas atienden sólo al 9\% de la matrícula estudiantil (La Tercera, junio 7 2003, p. 3). Dado que no hay evidencia que sugiera que en estas escuelas los estudiantes aprendan más, este hallazgo indica que hay serias imperfecciones en los mecanismos por los cuales la selección de líderes identifica talento.

En el caso de Colombia, crear las condiciones para reducir la pobreza requerirá atender a los desafíos de la tradicional fragmentación del poder en el país, la desintegración que resulta de la difícil geografía en Colombia, el que más de $60 \%$ de la población vive bajo la línea de pobreza y el que la desigualdad de ingresos en Colombia es la más alta de América Latina, luego de la de Brasil. Habrá, además que ayudar a las personas a reemplazar en sus mentes y en sus corazones las prácticas y costumbres desarrolladas durante los prolongados períodos de violencia que caracterizaron el siglo pasado, donde los homicidios, los secuestros y los crímenes contra la propiedad se hicieron práctica común. Es necesario que las escuelas asuman pronto la responsabilidad de enseñar a vivir en la legalidad, a respetar la vida y los derechos fundamentales de todas las personas, humanos, civiles y el derecho a la propiedad.

Demostrando que las escuelas pueden hacer esto con efectividad, contribuirán también a demostrar que el Estado no ha colapsado y también que la acción del Estado esta orientado a la búsqueda del objetivo de justicia social. Todo esto contribuirá a consolidar la paz.

En el caso de Colombia, hay dos desafíos relacionados con el objetivo de educar a todos. Por una parte, la creciente deserción escolar, y por otra, la exclusión desproporcionada de los grupos de menores ingresos del acceso a la educación secundaria y universitaria. Durante los últimos cincuenta años, Colombia logró expandir notablemente el acceso inicial a la educación primaria (a pesar de que ya la constitución de 1886, establecía el derecho a la educación primaria universal y gratuita). Como resultado, la gran mayoría de los niños inician actualmente el primer grado, con diferencias relativamente menores en la oportunidad de acceso inicial de distintos grupos socioeconómicos. Sin embargo, sólo una pequeña proporción de los niños que inician la escuela primaria la terminan; la mayoría de quienes desertan son los niños de las familias más pobres. Esto resulta en dos consecuencias graves para el funcionamiento de una democracia y para la paz. Por una parte, los niveles educativos de la población son bajos $y$, por otra parte, hay brechas educativas significativas entre distintos grupos sociales que sugieren que las oportunidades educativas reflejan las diferencias sociales de origen entre las personas.

En Colombia, el nivel educativo de la población económicamente activa es muy inferior a los niveles educativos de la población en países de la OECD. EI 39\% de la población en Colombia ha alcanzado apenas alguna educación primaria, el 7 \% no tiene educación, el $21 \%$ ha cursado alguna educación secundaria y sólo han completado la secundaria el $20 \%$. El $5.6 \%$ han cursado pero no concluido estudios universitarios y el $8 \%$ han concluido estudios universitarios ${ }^{36}$. Esto contrasta con promedios en la OECD donde $16 \%$ tiene sólo educación primaria y un $20 \%$ adicional sólo educación secundaria. En otras palabras, en promedio 2.3 de cada 5 personas en Colombia tienen apenas educación primaria o menos, comparado con 0.8 de cada 5 personas que tienen ese nivel en los países de la OECD. Por otra parte, 3 de cada 5 personas en los países de la OECD han completado al menos el nivel superior de educación secundaria en comparación con Colombia, donde apenas 1.7 de cada 5 personas ha completado este nivel. El contraste es claro: un niño

\footnotetext{
${ }^{36}$ SARMIENTO-GÓMEZ, Alfredo, "Política y Equidad Educativas en Colombia", en REIMERS, F. (Ed). Distintas Escuelas, diferentes oportunidades. Los retos para la igualdad de oportunidades en Latinoamérica, Madrid, Editorial Arco, La Muralla, 2002, p. 347.
} 
nacido en Colombia tiene una probabilidad de terminar apenas la primaria que es 3 veces la que tiene un niño nacido en la OECD, mientras que un niño nacido en un país de la OECD tiene una probabilidad de completar la secundaria, que es 1.8 veces la de uno nacido en Colombia.

El problema de la baja escolaridad en Colombia se agrava porque al concentrarse la menor oportunidad educativa entre los niños de las familias más pobres; esto reproduce el círculo vicioso de la pobreza. De este modo, las desiguales oportunidades educativas pueden ser percibidas como una señal de insuficiente interés por parte del Estado, por la justicia y por el bienestar de los más pobres. Para las familias más pobres que ven a sus hijos no aprender a pesar de los esfuerzos enormes que representa asistir a la escuela, este fracaso es una vivencia muy cercana del colapso del Estado. Esta vivencia hace a sus víctimas terreno fértil para el reclutamiento por grupos interesados en perpetuar las condiciones de ilegalidad, de irrespeto a la vida, a la propiedad, contribuyendo a socavar las reglas mínimas que permiten el funcionamiento de una sociedad.

Quienes no acceden a completar la educación básica, y por lo tanto a los niveles superiores de educación, son los más pobres. En Colombia la mayoría de los niños comienzan el primer grado en algún momento en su vida. En el año 2000 el 99\% de los niños de 12 años en las familias con el 20\% con más ingresos habían estado matriculados alguna vez en la escuela, y entre el $40 \%$ de las familias con menos ingresos el $96 \%$ de los niños había estado matriculados alguna vez en la escuela, como puede verse en el cuadro 9. Sin embargo, esta relativa igualdad en la oportunidad inicial de matricularse en la escuela no resulta en iguales oportunidades de permanecer en la escuela durante el tiempo suficiente para culminar sexto grado, o para culminar la educación básica de nueve grados. A la edad de 12 años seguían matriculados en la escuela todos los niños cuyas familias se encontraban en el $20 \%$ con más ingresos en la población, en comparación con el $86 \%$ de los niños cuyas familias se encontraban entre el $40 \%$ con menos ingresos en la población, por haber desertado el $14 \%$ del $96 \%$ que inició su escolaridad alguna vez. Entre los 15 y los 19 años, si bien el $92 \%$ de los niños en el $20 \%$ de las familias con más ingresos han aprobado seis años de escolaridad primaria, sólo la mitad de los niños en el $40 \%$ con menos ingresos han aprobado seis años. A la misma edad, mientras que el $73 \%$ de los niños en el $20 \%$ de las familias con más ingresos han aprobado nueve años de escolaridad básica, sólo uno de cada cuatro niños en el $40 \%$ de las familias con menos ingresos han aprobado ese nivel de escolaridad básica.

Cuadro 9. Probabilidad de estar matriculado a varios niveles y de haber alcanzado sexto $y$ noveno grado a la edad de 15-19 para distintos grupos de ingreso, en Colombia, en el año 2000

Más ingresos $40 \%$ de ingresos Menores ingresos $20 \%$ más rico $20 \%$ medios $40 \%$ $40 \%$ más pobre

Proporción de quienes estuvieron matriculados alguna vez entre los que tienen 12 años 0.99 0.99 0.96 $103 \%$

Proporción de quienes están matriculados en la escuela a la edad de 12 años 0.99 0.95 0.83 $119 \%$

Proporción de quienes han aprobado sexto grado (edad 15 a 19 años)
0.92
0.88
0.52
$177 \%$

Proporción de quienes han aprobado noveno gado (edad 15 a 19 años)
0.73
0.61
0.25
$292 \%$

Fuente: World Bank. Educational Attainment and Enrollment Around the http://www.worldbank.org/research/projects/edattain/edattain.htm (accesada 11 de junio de 2002).

World. 
El problema de las altas tasas de deserción escolar entre los grupos más pobres se ve agravado porque la deserción escolar ha estado aumentando en Colombia en los últimos años, lo cual sugiere que las brechas educativas entre grupos sociales aumentaran y que la escolaridad promedio de la población disminuirá aún más en los años venideros, aumentando todavía más las brechas con los países de la OECD y las brechas educativas entre diferentes grupos sociales, y probablemente debilitando aún más las competencias para ejercer ciudadanía asociadas con altos niveles de escolaridad. Es fundamental llevar adelante estudios que permitan conocer quiénes son los estudiantes que desertan de la escuela -ya es sabido que son fundamentalmente los más pobres, pero no todos los pobres desertan-y por qué lo hacen.

Si bien es posible que haya factores extra-escolares que incidan en la deserción (la violencia política que obliga a las familias a desplazarse, el deterioro de la situación económica de las familias, tal vez la percepción de que no hay opciones de empleo que justifiquen el esfuerzo de alcanzar niveles superiores de educación), es fundamental examinar cuál es la responsabilidad de la escuela por la deserción y buscar opciones de intervención allí donde ellas están más al alcance de la acción publica; es decir, en el sistema educativo. Decir el sistema educativo, sin embargo, es llevar el nivel de análisis más allá de la escuela específica que un niño abandona, pues hay circunstancias donde no es posible desde las escuelas que los niños abandonan incidir en las causas del problema. Así, por ejemplo, cuando una familia abandona su lugar de residencia porque las condiciones de violencia en esa zona la obliga a ello, hay poco que las escuelas mismas que van perdiendo a sus estudiantes podrían hacer para retenerlos, pues no pueden ellas resolver el problema de la violencia. Lo que sí puede el sistema educativo hacer es plantearse cómo atender a las necesidades educativas de los niños que se insertan como desplazados en nuevas comunidades; por ejemplo, flexibilizando las normas de inscripción para permitir que niños desplazados se matriculen en cualquier momento del año, creando programas de transición y de apoyo en la escuela para desplazados y coordinando con otras instituciones locales la provisión de servicios de salud mental para los niños desplazados y de sus familias.

Desde el punto de vista de contribuir a la democracia, a la estabilidad política y a la paz, hay varias razones de peso para interesarse en los niños que se van de la escuela antes de completar su educación fundamental. Una es que quienes se van proceden fundamentalmente de los sectores más pobres de la sociedad; al hacerlo pierden la principal oportunidad de las familias de mejorar de una generación a otra sus opciones de vida. Uno de los más claros rasgos que diferencian hoy en día en Colombia a grupos con distintos perfiles de ingreso, son sus distintos niveles educativos. En la medida en que los hijos de los pobres abandonen la escuela antes que los demás, esto contribuirá a reproducir el círculo vicioso de la pobreza ${ }^{37}$. Una segunda razón es que la desincorporación de los niños de la escuela, sin competencias que permitan opciones laborales bien remuneradas, y sin ocupación, aumentan la vulnerabilidad de estos niños, convirtiéndolos en potenciales instrumentos para la perpetuación de la violencia en sus diversas manifestaciones. Los jóvenes desocupados y aburridos pueden encontrar estimulación y sentido para sus vidas en actividades al margen de la ley. Una tercera razón es que al abandonar la escuela en grandes números se reducen las posibilidades

\footnotetext{
${ }^{37}$ En 1997 el 10\% más pobre de la población en edad laboral había aprobado 3 años de escolaridad, comparado con 12 años de escolaridad entre el 10\% de la población con más ingresos. El 30\% más pobre tenía menos de 5 años de escolaridad aprobada y el 30\% con más ingresos había aprobado al menos 8 años de escolaridad. (Sarmiento-Gómez, Alfredo, "Política y Equidad Educativas en Colombia", en Reimers, F. Ed. Distintas Escuelas, diferentes oportunidades. Madrid, Editorial Arco, La Muralla, 2002, pp. 327-387, p. 342.)
} 
agregadas del país de generar los bienes y servicios que permitan mejorar las condiciones de vida de toda la población. Finalmente, es el abandono de la escuela, antes que la falta de acceso inicial a ella, la causa principal de que la población más pobre no tenga niveles más altos de escolaridad. El enorme esfuerzo que ha representado para el Estado y para las familias el desarrollo de una cultura que valora la educación lo suficiente para aceptar y esperar que todos los niños sean matriculados en el primer grado de educación primaria, se ve minado cuando los niños abandonan la escuela, en particular antes de culminar la escolarización básica. El aumento reciente de los niveles de deserción es una señal alarmante de que una cultura alternativa, un nuevo conjunto de significados compartidos empieza a instalarse entre amplios grupos de la población y concretamente entre los niños que abandonan la escuela, donde el no terminar los estudios de primaria o el nivel de la educación básica aparecen como opciones de vida cada vez más aceptables.

Un reciente estudio realizado por Sarmiento, Tovar y Alam, muestra claramente cómo el porcentaje de niños que llegan a quinto grado en Colombia $(73 \%)$ es inferior al de otros países con índices de desarrollo humano comparables, incluidos México (86\%) y Venezuela $(89 \%)^{38}$. El mismo estudio confirma que son los niños más pobres quienes, como resultado de la deserción temprana, tienen menos probabilidad de acceder a la educación secundaria. Entre los 7 y los 11 años, el 93\% de los niños asisten a la escuela, para el $10 \%$ más pobre sólo el $88 \%$, mientras que para el $10 \%$ con más ingresos el $98 \%$ asiste. Entre los 12 y los 17 años, el porcentaje que asiste a la escuela cae a 60\% para el $10 \%$ más pobre, frente a $84 \%$ para el $10 \%$ con más ingresos. Entre los 18 y los 25 años sólo el $11 \%$ del $10 \%$ más pobre asiste a la escuela, comparado con el $27 \%$ entre el $10 \%$ con más ingresos ${ }^{39}$. En síntesis, es claro que quienes se van de la escuela son los más pobres y que con ello las brechas de oportunidad educativa crecen exponencialmente. Las brechas de oportunidad de estar estudiando entre ricos y pobres, de $10 \%$ entre los 7 y 11 años, son tres veces mayores entre los 12 y los 17 años, y seis veces mayores entre los 18 y los 25 años.

Un hallazgo fundamental y de gravísimas implicaciones del estudio anteriormente mencionado es que la proporción de estudiantes que asisten a la escuela ha comenzado a disminuir para los grupos más pobres a partir de 1997. Por ejemplo, entre los 7 y 11 años, la asistencia escolar para el 10\% más pobre disminuye de $92 \%$ en 1997 a $88 \%$ en 2000 , para el siguiente $10 \%$ de ingreso de $94 \%$ a $90 \%$, para el siguiente $10 \%$ disminuyó de $97 \%$ a $89 \%$. En todos los demás grupos de ingreso la asistencia escolar aumentó. Como resultado, las brechas de oportunidad mencionadas están aumentando.

Disminuciones aún más dramáticas se observan en la asistencia escolar de los cuatro deciles más pobres entre 12 y 17 años, mientras que la asistencia escolar aumenta para todos los demás deciles de ingreso. Para el decil más pobre la asistencia de quienes tienen entre 12 y 17 años cae de $69 \%$ en 1997 a $60 \%$ en el 2000 , para el siguiente decil cae del $73 \%$ al $59 \%$, para el siguiente decil del $84 \%$ al $65 \%$, para el siguiente decil de $80 \%$ a $66 \%$. Es decir, a partir de 1997 los hijos del 30-40\% más pobre del país pierden oportunidades de acceso a la educación que ya habían alcanzado, ello mientras los hijos de los restantes grupos de ingreso aumentan sus tasas de asistencia escolar. El porcentaje de asistencia es ligeramente menor entre los niños que entre las niñas para el grupo de 12 a 17 años (75\% vs. $77 \%$ ).

\footnotetext{
${ }^{38}$ SARMIENTO-GÓMEZ, A.; TOVAR, L. y ALAM, C., Situación de la Educación Básica, Media y Superior. Casa Editoral El Tiempo, 2002, p. 44

${ }^{39}$ Ibíd., p. 32.

Digitalizado por RED ACADEMICA
} 
Es posible que estos aumentos de la deserción escolar se deban a la profundización de la recesión económica, también podrían deberse a desplazamientos resultantes de la escalada de violencia política. Según datos de CODEES, se desplazan actualmente 42 personas cada hora por causa de la violencia ${ }^{40}$. La disrupción, al menos temporal, que estos desplazamientos causan en las oportunidades de estudio de los hijos de estas familias desplazadas, es obvia. Es posible, además, que una vez interrumpidas las trayectorias educativas de estos estudiantes y como consecuencia de las múltiples vulnerabilidades de las familias desplazadas, esta deserción de la escuela sea permanente. Aquellos estudiantes que se van de la escuela por el desplazamiento forzoso de sus familias son en su mayoría pobres y de origen rural; de este modo la violencia política en Colombia estaría robando a los hijos de los pobres las posibilidades de educarse y con ello estaría aumentando sus condiciones de marginación social, cuando no condenándolos a servir de instrumentos involuntarios de la violencia misma.

Considerando la evidencia existente en otros contextos que sugiere que la deserción es un proceso multicausado y que a ella contribuye la baja calidad de la oferta educativa que resulta inicialmente en repitencia y eventualmente en la expulsión de la escuela, es posible también que la deserción en Colombia -la más nueva expresada en los aumentos a partir de 1997 mencionados, así como los niveles preexistentes de deserción- resulte en parte de la baja calidad de la oferta educativa. Los niños y sus familias toman la decisión de abandonar la escuela, en parte porque no perciben que los beneficios que ella les ofrece justifican los enormes esfuerzos que asistir representa.

El mismo estudio mencionado muestra que las más altas tasas de deserción ocurren en primer grado de primaria (18\%) y en sexto grado de secundaria (15\%). Las tasas de deserción son significativamente más altas en las escuelas rurales que en las urbanas y en las escuelas oficiales que en las privadas. Los autores de este estudio atribuyen a la crisis económica el significativo aumento de las tasas de deserción en escuelas privadas y el aumento de las tasas de deserción en escuelas oficiales secundarias, a partir de 1997.

Analizando los resultados de la encuesta de condiciones de vida realizada en 1997, este estudio encuentra que la principal causa a la que las familias atribuyen que sus hijos no estén en la escuela son los costos que para las familias tiene la educación de sus hijos (44\% de los estudiantes entre 7 y 11 años y $35 \%$ de aquellos entre 12 y 17 años) seguida por 'No le gusta' (14\% de los estudiantes de 7 a 11 años y $29 \%$ de aquellos entre 12 y 17 años).

Estos resultados sugieren que las principales áreas sobre las que se podría incidir en los niveles de deserción (sobre la base de información proporcionada por las familias en 1997) serían los costos y la falta de atractivo de la educación secundaria para algunos de los jóvenes. Es posible que los mismos factores expliquen el aumento de la deserción a partir de 1997 como resultado de la acentuación de la crisis económica. Pero también es posible que nuevos factores expliquen la 'nueva deserción', en particular en los primeros grados de primaria.

Avanzar en reducir la proporción de los estudiantes que se van, requerirá avanzar en la comprensión del problema, en la identificación de opciones de acción y en la implementación de cambios en la escuela y en el sistema educativo.

\footnotetext{
${ }^{40}$ www.codhes.org.co

Digitalizado por RED ACADEMICA
} 
Los bajos niveles de escolaridad de la población son apenas la punta más visible de un problema de profundas dimensiones y complejidad. Muy pocos de los estudiantes latinoamericanos han alcanzado, a la edad de 15 años, competencias de lecto escritura, matemáticas o científicas satisfactorias. Para regresar al estudio de la OCDE, mencionado antes, menos del $1 \%$ de los estudiantes latinoamericanos de 15 años son capaces de contestar adecuadamente preguntas que requieren competencias de lectura sofisticadas, las cuales son vitales en economías basadas en el conocimiento, tales como comprender información difícil de encontrar en textos con los que se tiene poca familiaridad, o demostrar comprensión de la información presentada en dichos textos, o inferir qué información en dichos textos es relevante a una tarea de resolución de problemas. A la vez, sólo ese ínfimo porcentaje de los estudiantes pueden evaluar críticamente y formular hipótesis con base en conocimiento especializado 0 asimilar conceptos contrarios a las expectativas de sentido común. Estos bajísimos porcentajes de estudiantes que pueden leer con comprensión satisfactoria hay que compararlos con el $10 \%$ en promedio en la OCDE, o el $17 \%$ de los estudiantes en Canadá y el $12 \%$ en los Estados Unidos ${ }^{41}$. Al mismo tiempo, una gran cantidad de estudiantes latinoamericanos no tienen, a la edad de 15 años, competencias mínimas lectoras que les permitan identificar la idea principal en un texto. Mientras que en la OECD tan solo el 6\% de los estudiantes no pudieron demostrar este nivel más básico de comprensión lectora, este grupo alcanzó el 23\% en Argentina y Brasil, $20 \%$ en Chile, $16 \%$ en México y $54 \%$ en Perú ${ }^{42}$.

Otros estudios internacionales comparados de niveles de logro académico consistentemente muestran que los estudiantes latinoamericanos obtienen los más bajos puntajes. Esto incluye un estudio de lectura realizado en 1989 en el que los estudiantes de Venezuela que iniciaron su educación a comienzos de los ochenta, obtuvieron resultados entre los más bajos en el mundo ${ }^{43}$, así como un estudio de matemática y ciencia llevado a cabo en 1991 en el que estudiantes brasileños que igualmente iniciaron su educación a comienzos de los ochenta obtuvieron desempeños inferiores a sus pares en Corea, Taiwán, España, Estados Unidos y Portugal ${ }^{44}$.

Un estudio comparado llevado a cabo por UNESCO, en 1998, del desempeño estudiantil de estudiantes de cuarto grado en 12 países latinoamericanos; es decir, de estudiantes que iniciaron su escolarización en los noventa, muestra que los resultados son bastante parecidos en todos los países de la región; las diferencias en los resultados obtenidos por los estudiantes en las pruebas de lectura y matemática entre los países fueron de menos de una desviación estándar ${ }^{45}$.

Los bajos niveles de aprendizaje de los estudiantes chilenos, colombianos y mexicanos que iniciaron su escolarización en la década de los ochenta, son confirmados por el Tercer Estudio de Matemáticas y Ciencias (TIMSS). Este estudio, que evaluó el desempeño académico de estudiantes en 39 países del mundo en séptimo y octavo grados, a comienzos de los noventa, muestra que sólo los estudiantes de Sudáfrica, con su larga historia de discriminación racial expresada en bajísimas oportunidades

\footnotetext{
41 Ver OECD, Knowledge and Skills for Life. Paris, Organization for Economic Cooperation and Development, 2001.

42 OECD, Literacy Skills for the World of Tomorrow. Further Results from PISA 2000. Paris, Organization for Economic Cooperation and Development, 2003, p. 274.

${ }_{43}$ ELLEY, W.B., How in the World do Students Read? (Newark, Delaware: International Reading Association, 1992).

${ }^{44}$ ETS, 1992.

45 UNESCO-OREALC, Primer Estudio Internacional Comparativo sobre Lenguaje, Matemática y Factores Asociados en Tercero y Cuarto Grado. Santiago, UNESCO, 1998. 
educativas en las escuelas para los estudiantes negros, tienen niveles de desempeño ligeramente más bajos que los estudiantes de Colombia. En una escala de 800 puntos, los estudiantes colombianos de séptimo grado obtuvieron en promedio 369 puntos en matemáticas, comparados con un promedio en el conjunto de los 39 países de 484 puntos, y con un promedio de 476 puntos en Estados Unidos y de 494 puntos en Canadá $^{46}$. Los resultados en la prueba de ciencias de octavo grado fueron iguales de bajos, promediando 411 puntos entre los estudiantes colombianos, con relación a un promedio de 516 para el conjunto de los países. De nuevo, sólo los estudiantes de Sudáfrica obtuvieron puntajes inferiores a los estudiantes colombianos ${ }^{47}$.

Colombia, comparte estos bajos niveles de desempeño de sus estudiantes con otros países latinoamericanos que participaron en dicho estudio, Chile y México. México se retiró al conocer resultados preliminares que indicaban que sus estudiantes tenían desempeños que se encontraban entre los más bajos del mundo. Chile participó en una segunda administración de este estudio, obteniendo promedios de 392 en matemáticas y 420 en ciencias, muy por debajo del promedio internacional en esta segunda administración de 487 y 488, respectivamente ${ }^{48}$.

Son los estudiantes pobres, los que viven en aldeas rurales y los indígenas y mulatos los que tienen los más bajos niveles de aprendizaje, y en consecuencia los que tienen menores oportunidades de acceder a la escuela secundaria y a la universidad. Como he señalado, es el acceso a estos niveles educativos superiores el que permite desarrollar más confianza interpersonal, mayores actitudes democráticas y competencias que brindan más oportunidad de acceso a empleos productivos.

El lograr que los hijos de los pobres tengan acceso a la secundaria y a la universidad, y que estén preparados para desempeñarse con éxito en estos niveles, es uno de los principales desafíos de la educación, habida cuenta que uno de los factores que más inciden en el desempeño educativo de las personas, tanto en los años de escolaridad que se alcanzan como en el aprovechamiento escolar, es el nivel educativo de los padres. El desempeño escolar de los estudiantes, y su capacidad de alcanzar niveles superiores de escolaridad, dependen del apoyo que reciban de sus familias y del que reciban de sus maestras. Para aquellos estudiantes que son los primeros en sus familias en acceder a un nivel educativo, tener buenas maestras es mucho más importante que para quienes tienen en casa quienes comprenden lo que se espera de ellos en la escuela, quienes pueden conectar las demandas en un curso en particular con la trayectoria futura educativa de los estudiantes y quienes pueden apoyar a los niños a integrar los pequeños logros y fracasos diarios, asociados a la cotidianeidad de la escuela en un plan de largo plazo para lograr las aspiraciones personales y profesionales del estudiante. Las buenas maestras para los estudiantes, que son los primeros en sus familias en acceder a un curso y nivel educativo son aquellas que pueden situar su práctica en el contexto de las necesidades y perspectivas de esos estudiantes concretos. Son quienes pueden no sólo presentar contenidos educativos con claridad y en formas que los estudiantes puedan integrar al conjunto de significados que forman parte de su experiencia, sino que pueden atender a sus estudiantes como personas integrales, comprendiendo y atendiendo sus

${ }^{46}$ BEATON, A.; MULLIS, I.; MARTIN, M., GONZÁLEZ, E.; KELLY, D. and SMITH, T., Mathematics Achievement in the Middle school Years: IEA's Third International Mathematics and Science Study (TIMSS). International Association for the Evaluation of Educational Achievement. Chestnut Hill, MA. Boston College, 1996, p. 23.

${ }^{47}$ BEATON, A.; MULLIS, I.; MARTIN, M., GONZÁLEZ, E.; KELLY, D. and SMITH, T., Science Achievement in the Middle school Years: IEA's Third International Mathematics and Science Study (TIMSS). International Association for the Evaluation of Educational Achievement. Chestnut Hill, MA. Boston College, 1996, p. 23.

${ }^{48}$ BEATON et alii. 2000. 
necesidades de desarrollo emocional y social y que pueden ayudar explícitamente a los estudiantes a construir elevadas aspiraciones sobre su propio futuro, a desarrollar marcos de referencia éticos para orientar sus vidas en el contexto de las comunidades y sociedades en las que están integrados y a construir un plan graduado de logros académicos y personales para satisfacer sus aspiraciones y para superar las dificultades y obstáculos derivados de las carencias materiales y de las demandas propias de la vida en ambientes de pobreza.

Debido a que la educación es aún un privilegio en América Latina, son muchos los estudiantes cuyos padres tienen bajos niveles de escolaridad. El cuadro 10 muestra el porcentaje de estudiantes de tercero y cuarto grados de primaria, cuyos tutores (la persona señalada como jefe de hogar,) tienen distintos niveles de escolaridad. En Argentina, por ejemplo, entre los estudiantes que asisten a escuelas públicas en ciudades de más de un millón de habitantes, $15 \%$ de los alumnos tienen tutores que no han completado aún la primaria, con un 32\% adicional que apenas ha completado la primaria. Es decir, casi la mitad de los alumnos proceden de hogares donde matricularse más allá de la escuela primaria significaría ser la primera generación en lograr este nivel educativo. En Brasil, el porcentaje de alumnos, cuyos tutores no han completado la educación primaria, es $67 \%$ en escuelas públicas en ciudades grandes, y muy superior en zonas rurales $(84 \%)$.

Cuadro 10. Niveles de educación de los tutores de estudiantes de tercero y cuarto grado de primaria, en varios países de América Latina, en 1998 (porcentajes)

\section{Sin Primaria Primaria Secundaria Secundaria Superior Superior instrucción incompleta completa incompleta comp. incompleta. comp.}

Ciudades de más de 1 millón de habitantes. Escuelas Públicas

\begin{tabular}{lccccccc} 
Argentina & $1 \%$ & $14 \%$ & $32 \%$ & $15 \%$ & $15 \%$ & $9 \%$ & $14 \%$ \\
Bolivia & $1 \%$ & $19 \%$ & $19 \%$ & $24 \%$ & $23 \%$ & $9 \%$ & $6 \%$ \\
Brasil & $14 \%$ & $53 \%$ & $9 \%$ & $6 \%$ & $12 \%$ & $2 \%$ & $4 \%$ \\
Chile & $3 \%$ & $36 \%$ & $12 \%$ & $26 \%$ & $20 \%$ & $2 \%$ & $1 \%$ \\
Colombia & $0 \%$ & $27 \%$ & $17 \%$ & $30 \%$ & $15 \%$ & $4 \%$ & $7 \%$ \\
Cuba & $0 \%$ & $2 \%$ & $2 \%$ & $7 \%$ & $33 \%$ & $22 \%$ & $33 \%$ \\
Honduras & $4 \%$ & $32 \%$ & $27 \%$ & $9 \%$ & $19 \%$ & $7 \%$ & $1 \%$ \\
México & $0 \%$ & $19 \%$ & $25 \%$ & $41 \%$ & $8 \%$ & $3 \%$ & $4 \%$ \\
Perú & $2 \%$ & $15 \%$ & $12 \%$ & $27 \%$ & $20 \%$ & $13 \%$ & $11 \%$ \\
República & & & & & & & \\
Dominicana & $0 \%$ & $31 \%$ & $12 \%$ & $16 \%$ & $19 \%$ & $15 \%$ & $8 \%$ \\
Venezuela & $3 \%$ & $18 \%$ & $19 \%$ & $26 \%$ & $22 \%$ & $4 \%$ & $7 \%$ \\
Ciudades de más de 1 millón & de habitantes. Escuelas Privadas & & & \\
Argentina & $0 \%$ & $2 \%$ & $8 \%$ & $9 \%$ & $23 \%$ & $19 \%$ & $38 \%$ \\
Bolivia & $0 \%$ & $5 \%$ & $3 \%$ & $10 \%$ & $20 \%$ & $25 \%$ & $36 \%$ \\
Brasil & $1 \%$ & $12 \%$ & $9 \%$ & $12 \%$ & $24 \%$ & $11 \%$ & $32 \%$ \\
Chile & $0 \%$ & $7 \%$ & $9 \%$ & $22 \%$ & $42 \%$ & $8 \%$ & $11 \%$ \\
Colombia & $0 \%$ & $14 \%$ & $10 \%$ & $25 \%$ & $27 \%$ & $12 \%$ & $12 \%$ \\
\hline Honduras & $0 \%$ & $5 \%$ & $6 \%$ & $9 \%$ & $33 \%$ & $22 \%$ & $24 \%$ \\
México & $0 \%$ & $2 \%$ & $11 \%$ & $27 \%$ & $19 \%$ & $10 \%$ & $32 \%$ \\
\hline $\begin{array}{l}\text { Perú } \\
\text { República }\end{array}$ & $0 \%$ & $1 \%$ & $3 \%$ & $11 \%$ & $9 \%$ & $21 \%$ & $54 \%$ \\
Dominicana & $0 \%$ & $14 \%$ & $9 \%$ & $11 \%$ & $16 \%$ & $20 \%$ & $29 \%$ \\
Venezuela & & $11 \%$ & $9 \%$ & $27 \%$ & $22 \%$ & $11 \%$ & $20 \%$
\end{tabular}




\begin{tabular}{|c|c|c|c|c|c|c|c|}
\hline Argentina & $1 \%$ & $19 \%$ & $27 \%$ & $18 \%$ & $18 \%$ & $7 \%$ & $9 \%$ \\
\hline Bolivia & $3 \%$ & $27 \%$ & $14 \%$ & $24 \%$ & $18 \%$ & $8 \%$ & $5 \%$ \\
\hline Brasil & $10 \%$ & $59 \%$ & $9 \%$ & $7 \%$ & $11 \%$ & $2 \%$ & $3 \%$ \\
\hline Chile & $1 \%$ & $25 \%$ & $14 \%$ & $26 \%$ & $24 \%$ & $5 \%$ & $6 \%$ \\
\hline Colombia & $4 \%$ & $33 \%$ & $16 \%$ & $23 \%$ & $17 \%$ & $3 \%$ & $4 \%$ \\
\hline Cuba & $3 \%$ & $3 \%$ & $3 \%$ & $8 \%$ & $31 \%$ & $22 \%$ & $30 \%$ \\
\hline Honduras & $13 \%$ & $37 \%$ & $24 \%$ & $8 \%$ & $14 \%$ & $3 \%$ & $1 \%$ \\
\hline México & $0 \%$ & $31 \%$ & $21 \%$ & $29 \%$ & $7 \%$ & $5 \%$ & $7 \%$ \\
\hline Paraguay & $1 \%$ & $29 \%$ & $23 \%$ & $15 \%$ & $16 \%$ & $9 \%$ & $7 \%$ \\
\hline Perú & $8 \%$ & $25 \%$ & $22 \%$ & $16 \%$ & $12 \%$ & $7 \%$ & $8 \%$ \\
\hline \multicolumn{8}{|l|}{ República } \\
\hline Dominicana & $4 \%$ & $33 \%$ & $12 \%$ & $21 \%$ & $15 \%$ & $8 \%$ & $7 \%$ \\
\hline Venezuela & $4 \%$ & $23 \%$ & $21 \%$ & $23 \%$ & $14 \%$ & $9 \%$ & $7 \%$ \\
\hline \multicolumn{8}{|c|}{ Ciudades entre 2,500 y 1 millón de habitantes. Escuelas Privadas } \\
\hline Argentina & $1 \%$ & $5 \%$ & $11 \%$ & $12 \%$ & $21 \%$ & $18 \%$ & $32 \%$ \\
\hline Bolivia & $5 \%$ & $18 \%$ & $13 \%$ & $14 \%$ & $19 \%$ & $12 \%$ & $18 \%$ \\
\hline Brasil & $3 \%$ & $24 \%$ & $6 \%$ & $9 \%$ & $30 \%$ & $9 \%$ & $19 \%$ \\
\hline Chile & $0 \%$ & $10 \%$ & $9 \%$ & $19 \%$ & $32 \%$ & $9 \%$ & $21 \%$ \\
\hline Colombia & $0 \%$ & $12 \%$ & $8 \%$ & $19 \%$ & $24 \%$ & $13 \%$ & $24 \%$ \\
\hline Honduras & $0 \%$ & $23 \%$ & $20 \%$ & $10 \%$ & $36 \%$ & $7 \%$ & $4 \%$ \\
\hline México & $0 \%$ & $8 \%$ & $7 \%$ & $28 \%$ & $17 \%$ & $10 \%$ & $30 \%$ \\
\hline Paraguay & $1 \%$ & $13 \%$ & $10 \%$ & $12 \%$ & $20 \%$ & $20 \%$ & $24 \%$ \\
\hline Perú & $3 \%$ & $10 \%$ & $10 \%$ & $14 \%$ & $19 \%$ & $17 \%$ & $27 \%$ \\
\hline \multicolumn{8}{|l|}{ República } \\
\hline Dominicana & $1 \%$ & $35 \%$ & $15 \%$ & $16 \%$ & $25 \%$ & $5 \%$ & $2 \%$ \\
\hline Venezuela & $14 \%$ & $9 \%$ & $15 \%$ & $16 \%$ & $15 \%$ & $31 \%$ & \\
\hline \multicolumn{8}{|c|}{ Ciudades de menos de 2,500 habitantes (zonas rurales. Escuelas Publicas } \\
\hline Argentina & $2 \%$ & $27 \%$ & $33 \%$ & $12 \%$ & $12 \%$ & $5 \%$ & $10 \%$ \\
\hline Bolivia & $6 \%$ & $44 \%$ & $22 \%$ & $12 \%$ & $11 \%$ & $2 \%$ & $3 \%$ \\
\hline Brasil & $13 \%$ & $71 \%$ & $8 \%$ & $2 \%$ & $4 \%$ & $2 \%$ & $1 \%$ \\
\hline Chile & $3 \%$ & $40 \%$ & $19 \%$ & $16 \%$ & $13 \%$ & $4 \%$ & $5 \%$ \\
\hline Colombia & $10 \%$ & $44 \%$ & $18 \%$ & $14 \%$ & $9 \%$ & $3 \%$ & $2 \%$ \\
\hline Cuba & $2 \%$ & $7 \%$ & $10 \%$ & $13 \%$ & $40 \%$ & $15 \%$ & $13 \%$ \\
\hline Honduras & $12 \%$ & $55 \%$ & $20 \%$ & $6 \%$ & $4 \%$ & $1 \%$ & $1 \%$ \\
\hline México & $0 \%$ & $42 \%$ & $24 \%$ & $23 \%$ & $5 \%$ & $2 \%$ & $4 \%$ \\
\hline Paraguay & $2 \%$ & $46 \%$ & $29 \%$ & $12 \%$ & $7 \%$ & $2 \%$ & $1 \%$ \\
\hline Perú & $12 \%$ & $35 \%$ & $24 \%$ & $14 \%$ & $9 \%$ & $3 \%$ & $4 \%$ \\
\hline \multicolumn{8}{|l|}{ República } \\
\hline Dominicana & $5 \%$ & $49 \%$ & $14 \%$ & $14 \%$ & $9 \%$ & $5 \%$ & $3 \%$ \\
\hline Venezuela & $10 \%$ & $40 \%$ & $22 \%$ & $17 \%$ & $9 \%$ & $2 \%$ & $2 \%$ \\
\hline
\end{tabular}

Fuente: Cálculos propios sobre datos recogidos por UNESCO-OREALC en la encuesta administrada a una muestra de escuelas para evaluar la calidad de la educación. 1998.

¿Cómo explicar la persistente desigualdad en los niveles de aprovechamiento escolar y en los niveles educativos que alcanzan estudiantes de distinto origen social?

Tres explicaciones muy populares en nuestros días sobre los menores logros educativos de los hijos de los pobres se centran en el funcionamiento del cerebro, en el papel de la familia y en las influencias del vecindario, de la comunidad. Estas explicaciones se centran en que hay una base material, neurológica, del funcionamiento mental que no es igual en todas las personas; es esta una re-edición contemporánea del viejo adagio "o que natura non da, Salamanca no lo presta'. Las explicaciones culturales sobre la influencia de la familia indican que los chicos están sólo una parte relativamente corta de sus vidas en las escuelas, el tipo de estimulación que reciben en casa, en la época crucial entre el nacimiento y el comienzo de la escolaridad, y en las horas en que no están en la escuela, son fundamentales en el desarrollo de habilidades cognoscitivas y en su desarrollo emocional y social. Finalmente, las explicaciones que hablan de la importancia 
del lugar de residencia destacan que las condiciones de vida en general, el tipo de actividades dominantes en la comunidad, los ejemplos, los incentivos que inciden sobre los estudiantes, juegan un papel en favorecer u obstaculizar el tipo de trabajo intelectual valorado por la escuela. Lo que ninguna de estas explicaciones hace es explicar qué papel juegan los maestros en promover el éxito escolar de los chicos. Al alejarse de la escuela, estas explicaciones sirven como profecías que se cumplen a sí mismas, perpetuando condiciones que hacen que los maestros, a pesar de las enormes esperanzas que en ellos tengan los chicos y sus familias, enseñen muy poco.

\section{La importancia de la buena enseñanza}

Los bajos niveles de aprendizaje de los estudiantes en las escuelas de América Latina, y los bajos porcentajes de estudiantes que completan la educación primaria y proceden a la secundaria se deben, en parte, a que la calidad de la enseñanza es deficiente; esto a pesar de que los profesores tratan de que sus estudiantes aprendan; es decir, de que hacen lo mejor que saben y pueden hacer. El cuadro 11 muestra que existe un alto porcentaje de estudiantes de tercero y cuarto grados de primaria que no entienden lo que el maestro les explica; este porcentaje es mayor en las escuelas públicas que en las privadas y en las zonas rurales que urbanas.

Cuadro 11. Porcentaje de alumnos de tercero y cuarto grados de primaria que entienden lo que el maestro explica

Entienden lo que el maestro explica

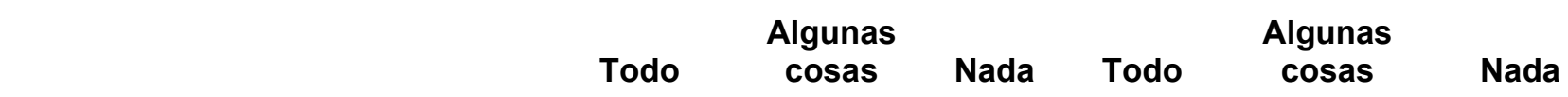

Ciudades de más de 1 millón de habitantes.

\begin{tabular}{lccc} 
& \multicolumn{3}{c}{ Escuelas Publicas } \\
Argentina & $66 \%$ & $33 \%$ & $1 \%$ \\
Bolivia & $64 \%$ & $33 \%$ & $2 \%$ \\
Brasil & $46 \%$ & $54 \%$ & $1 \%$ \\
Chile & $46 \%$ & $49 \%$ & $4 \%$ \\
Colombia & $62 \%$ & $36 \%$ & $2 \%$ \\
Cuba & $90 \%$ & $10 \%$ & $0 \%$ \\
Honduras & $71 \%$ & $27 \%$ & $2 \%$ \\
México & $60 \%$ & $39 \%$ & $1 \%$ \\
Perú & $63 \%$ & $35 \%$ & $2 \%$ \\
República Dominicana & $67 \%$ & $31 \%$ & $2 \%$ \\
Venezuela & $65 \%$ & $35 \%$ & $1 \%$ \\
Ciudades entre 2,500 y 1 millón de habitantes. & &
\end{tabular}

Ciudades entre 2,500 y 1 millón de habitantes.

Argentina
Bolivia
Brasil
Chile
Colombia
Cuba
Honduras
México
Paraguay
Digitalizado por RED ACADEMICA

\begin{tabular}{cccccc}
\multicolumn{2}{l}{ Escuelas Públicas } & \multicolumn{5}{c}{ Escuelas Privadas } \\
$61 \%$ & $37 \%$ & $2 \%$ & $57 \%$ & $41 \%$ & $2 \%$ \\
$65 \%$ & $32 \%$ & $2 \%$ & $69 \%$ & $30 \%$ & $1 \%$ \\
$52 \%$ & $47 \%$ & $1 \%$ & $53 \%$ & $47 \%$ & $0 \%$ \\
$51 \%$ & $47 \%$ & $2 \%$ & $50 \%$ & $49 \%$ & $1 \%$ \\
$62 \%$ & $36 \%$ & $2 \%$ & $64 \%$ & $35 \%$ & $0 \%$ \\
$86 \%$ & $13 \%$ & $0 \%$ & $0 \%$ & $0 \%$ & $0 \%$ \\
$64 \%$ & $34 \%$ & $2 \%$ & $70 \%$ & $30 \%$ & $0 \%$ \\
$62 \%$ & $36 \%$ & $1 \%$ & $60 \%$ & $40 \%$ & $0 \%$ \\
$74 \%$ & $24 \%$ & $2 \%$ & $71 \%$ & $28 \%$ & $1 \%$
\end{tabular}

\begin{tabular}{ccc}
\multicolumn{3}{c}{ Escuelas } \\
$69 \%$ & $29 \%$ & $2 \%$ \\
$69 \%$ & $31 \%$ & $0 \%$ \\
$53 \%$ & $46 \%$ & $1 \%$ \\
$42 \%$ & $56 \%$ & $2 \%$ \\
$62 \%$ & $38 \%$ & $0 \%$ \\
$0 \%$ & $0 \%$ & $0 \%$ \\
$66 \%$ & $30 \%$ & $3 \%$ \\
$66 \%$ & $33 \%$ & $1 \%$ \\
$56 \%$ & $43 \%$ & $1 \%$ \\
$69 \%$ & $30 \%$ & $1 \%$ \\
$74 \%$ & $26 \%$ & $1 \%$
\end{tabular}




\begin{tabular}{lccc} 
Perú & $64 \%$ & $33 \%$ & $3 \%$ \\
República Dominicana & $63 \%$ & $34 \%$ & $3 \%$ \\
Venezuela & $71 \%$ & $26 \%$ & $3 \%$ \\
Ciudades de menos de 2,500 habitantes & \multicolumn{3}{c}{ Eschas rurales). } \\
\multicolumn{4}{c}{ Escuelas Públicas } \\
Argentina & $57 \%$ & $40 \%$ & $3 \%$ \\
Bolivia & $60 \%$ & $37 \%$ & $4 \%$ \\
Brasil & $49 \%$ & $49 \%$ & $2 \%$ \\
Chile & $52 \%$ & $45 \%$ & $3 \%$ \\
Colombia & $54 \%$ & $45 \%$ & $1 \%$ \\
Cuba & $87 \%$ & $13 \%$ & $0 \%$ \\
Honduras & $68 \%$ & $30 \%$ & $2 \%$ \\
México & $60 \%$ & $39 \%$ & $1 \%$ \\
Paraguay & $63 \%$ & $33 \%$ & $4 \%$ \\
Perú & $53 \%$ & $44 \%$ & $3 \%$ \\
República Dominicana & $63 \%$ & $35 \%$ & $2 \%$ \\
Venezuela & $62 \%$ & $37 \%$ & $1 \%$
\end{tabular}

Fuente: Cálculos propios sobre datos recogidos por UNESCO-OREALC en la encuesta administrada a una muestra de escuelas para evaluar la calidad de la educación. 1998.

La forma en que las maestras explican, está, pues, fuera del alcance de $40 \%$ de los niños. Lo que es más grave, aquellos que menos entienden están menos inclinados a pedir ayuda adicional al maestro. Al preguntarle a los niños qué hacen cuando tienen dudas con una explicación, entre quienes entienden todo lo que el maestro explica, un porcentaje mayor pregunta de inmediato al maestro, entre quienes no entienden nada muy pocos preguntan de inmediato al maestro. Una proporción mucho mayor de los niños que no entienden las explicaciones de los profesores se apoya en sus compañeros o no hace nada.

Cuadro 12. Porcentaje de estudiantes de tercero y cuarto grados que piden aclaración de sus dudas por cuanto entienden las explicaciones de los maestros, en Colombia, en 1998

\section{Entienden lo que el maestro explica}

En caso de duda

Pregunta de inmediato
Pregunta después
Espera siguiente clase
Pregunta a otros
No pregunta
Total

$\begin{array}{cccc}\text { Todo } & \text { Algunas cosas } & \text { Nada } & \text { Total } \\ & & & \\ 75.7 \% & 64.0 \% & 26.7 \% & 70.7 \% \\ 10.1 \% & 10.7 \% & 22.2 \% & 10.5 \% \\ 4.7 \% & 8.4 \% & 22.2 \% & 6.3 \% \\ 5.5 \% & 11.4 \% & 11.1 \% & 7.8 \% \\ 3.9 \% & 5.5 \% & 17.8 \% & 4.7 \% \\ 100.0 \% & 100.0 \% & 100.0 \% & 100.0 \%\end{array}$

Fuente: Cálculos propios de datos procedentes de la encuesta administrada por el Ministerio de Educación y la Oficina Regional de UNESCO para América Latina y el Caribe (Laboratorio Latinoamericano de la Calidad de la Educación). Estrato Mega Ciudad se refiere a ciudades con más de 1 millón de habitantes. Urbano se refiere a ciudades de menos de 1 millón de habitantes.

Aparte de que un buen número de estudiantes no entiende las explicaciones de los profesores, las lecturas que hacen los maestros no son estimulantes para los estudiantes.

Al preguntarles que es lo que más les gustaba de la escuela, sólo $17 \%$ mencionaron como primera opción las lecturas de los profesores, y un $8 \%$ adicional mencionaron 
aprender, mientras que un $67 \%$ mencionaron el deporte. Como segunda opción un porcentaje mayor menciona aprender (46\%) pero tan solo $14 \%$ mencionan las lecturas del maestro como lo que más les gusta.

Cuadro 13. Porcentaje de estudiantes de tercero y cuarto grado que indican cuales son las actividades que más les gustan en la escuela en Colombia, en 1998

\begin{tabular}{l|ccccc} 
Primera opción & Deporte & $\begin{array}{c}\text { Lecturas } \\
\text { del maestro }\end{array}$ & Jugar & Aprender & Vacaciones \\
\hline Mega-Público & $64.3 \%$ & $16.7 \%$ & $9.6 \%$ & $8.3 \%$ & $1.1 \%$ \\
Mega-Privado & $67.6 \%$ & $15.7 \%$ & $7.8 \%$ & $8.3 \%$ & $.6 \%$ \\
Urbano-Público & $66.5 \%$ & $16.1 \%$ & $7.3 \%$ & $8.8 \%$ & $1.3 \%$ \\
Urbano-Privado & $67.5 \%$ & $13.7 \%$ & $8.7 \%$ & $9.1 \%$ & $1.0 \%$ \\
Rural & $67.5 \%$ & $19.9 \%$ & $6.5 \%$ & $6.1 \%$ & $.1 \%$ \\
Total & $66.8 \%$ & $16.9 \%$ & $7.6 \%$ & $7.9 \%$ & $.8 \%$ \\
Segunda opción & Deporte & Lecturas & Jugar & Aprender & Vacaciones \\
& \multicolumn{5}{|c}{ de maestro } \\
Mega-Público & $.7 \%$ & $11.3 \%$ & $13.4 \%$ & $41.1 \%$ & $33.6 \%$ \\
Mega-Privado & $.8 \%$ & $10.5 \%$ & $12.2 \%$ & $44.8 \%$ & $31.6 \%$ \\
Urbano-Público & $.3 \%$ & $17.2 \%$ & $13.5 \%$ & $45.5 \%$ & $23.5 \%$ \\
Urbano-Privado & $.4 \%$ & $9.4 \%$ & $10.7 \%$ & $41.1 \%$ & $38.3 \%$ \\
Rural & $.4 \%$ & $13.9 \%$ & $11.8 \%$ & $52.0 \%$ & $22.0 \%$ \\
Total & $.5 \%$ & $13.7 \%$ & $12.5 \%$ & $46.3 \%$ & $27.1 \%$
\end{tabular}

Fuente: Cálculos propios de datos procedentes de la encuesta administrada por el Ministerio de Educación y la Oficina Regional de UNESCO para América Latina y el Caribe (Laboratorio Latinoamericano de la Calidad de la Educación). Estrato Mega Ciudad se refiere a ciudades con más de 1 millón de habitantes. Urbano se refiere a ciudades de menos de 1 millón de habitantes.

¿Por qué aprenden tan poco en la escuela los estudiantes, a pesar de que les gusta asistir y de que perciben que los profesores hacen lo mejor que pueden y que saben? Sin duda, es ésta una pregunta a cuya respuesta contribuyen múltiples factores en interacción. Uno podría decir que es la pobreza misma, que incide en la salud de los estudiantes, en su capacidad de concentración y en el tiempo de que disponen para estudiar. Es muy probable que en países con enormes niveles de pobreza, a veces en aumento, estas condiciones materiales de vida jueguen un papel importante en facilitar la disposición de los estudiantes a aprender. Pero reducir las explicaciones del fracaso escolar a condiciones extra-escolares, si bien consistente con una larga tradición en América Latina, sería probablemente inadecuado. Dado que aún los estudiantes menos pobres aprenden relativamente menos que sus pares en otras naciones y dado que hay una amplia dispersión de los niveles de logro de los estudiantes más pobres, sugiere que hay condiciones propiamente educativas que contribuyen a los bajos resultados.

Otro conjunto de explicaciones posibles de estos pobres resultados las atribuiría a la forma en que se toman decisiones y administran programas en educación. El sector educativo ha servido por mucho tiempo para mantener estilos de gestión autoritarios, poco transparentes, cuando no la franca corrupción en la utilización de los recursos públicos a expensas de los estudiantes. Es posible que la mala administración, el autoritarismo y el uso de los recursos educativos para fines privados, hayan contribuido también su parte a las bajas capacidades de los estudiantes latinoamericanos.

Pero además de la pobreza y la mala gestión, quisiera proponer que en la búsqueda de alternativas para mejorar la educación, conviene comenzar por lo más inmediato, invisible tal vez por evidente, comenzar por la tarea del maestro. Cuando uno conversa con 
estudiantes y mira sus cuadernos y sus libros de texto, encuentra pistas para explicar el fracaso de los sistemas educativos: expectativas bajas de logro en los planes y programas de estudio, en los libros de texto y en el currículo implementado en el aula, objetivos difusos, poco específicos, de parte de los docentes, pedagogías inefectivas para desarrollar competencias de los estudiantes, materiales instruccionales deficientes, condiciones en las escuelas que distraen de la tarea pedagógica, relaciones colegiadas en la escuela que no apoyan la dedicación a la tarea docente y las altas expectativas. Son estos temas para una agenda de investigación que busque identificar cuáles son las condiciones en las que realmente se enseña y proponer opciones para mejorar la efectividad de las escuelas. Entre los factores cuya contribución es necesario investigar, están los niveles de exigencia del currículo, la calidad de los materiales educativos, los niveles de conocimiento de los profesores y las técnicas pedagógicas de los profesores y el clima instruccional en las escuelas y en el aula. Afortunadamente, existe ya en la región y fuera de ella abundante conocimiento derivado de investigación que puede servir para iniciar acciones de reforma, al tiempo que se profundiza el conocimiento existente realizando estudios y evaluaciones específicos al contexto de cada país.

En un clima de emergencia, el sentido común o el buen sentido de los administradores, puede fácilmente suplantar el conocimiento basado en investigación. No hay tiempo para detenerse demasiado a analizar las causas de los problemas, para estudiar allí donde hay vacíos en la comprensión y hay prisa por iniciar la acción, pues mañana es demasiado tarde. Hay dos riesgos asociados a este proceder. Un primer riesgo es que el sentido común refleje una visión parcial e incompleta de los hechos, en muchos casos teorías y supuestos no comprobados. En cierta forma, los deficientes logros de los sistemas educativos de la región ilustran a dónde conduce este tipo de improvisación y de desprecio por el conocimiento y la investigación. Durante la década pasada, por ejemplo, muchos países en la región experimentaron con diversas maneras de descentralizar la gestión educativa, a las escuelas, a entidades de gobierno local. A juzgar por los resultados en las comparaciones internacionales, estos experimentos reflejaron importantes vacíos conceptuales, se basaron en supuestos que los pobres resultados están lejos de validar. Un segundo riesgo es que, en ausencia de investigación, los debates sobre cómo mejorar la pedagogía reproduzcan debates ideológicos centenarios y un tanto estériles, que contribuyen a mantener las brechas entre quienes tienen responsabilidad por la gestión educativa y las comunidades académicas y de investigación. Ejemplos de estos debates seculares son, si es mejor, por ejemplo, enseñar a los niños con el método silábico o global, debates bastante superados, por cierto, como resultado de la investigación más reciente sobre el tema, o si eran mejores las normales que las universidades, o si es mejor una filosofía pedagógica más abierta que una más estructurada. Ante la decepción de estos interminables debates, que en ocasiones muestran mucha incapacidad para aterrizar discusiones de principios generales en recomendaciones concretas, podría ocurrir que bajo la urgencia de la emergencia se echara mano de eslóganes, de las reformas de moda en países vecinos o de un nuevo populismo educativo, un nuevo currículo, nuevos libros, computadores para las escuelas, nuevas edificaciones escolares. Sin prejuzgar si estos apoyos son o no necesarios, es difícil saber si serán suficientes sin conocer un poco más a fondo las razones por las cuales en el presente los niños no aprenden. En educación, a veces, condiciones que son necesarias para facilitar la buena enseñanza, no son suficientes. Es en descubrir el detalle donde la investigación puede ayudar a afinar el juicio de quienes toman decisiones de política. Por ejemplo, es fácil conocer que hay deficiencia de materiales instruccionales básicos en las escuelas de América Latina, como muestran los resultados de una encuesta administrada por los Ministerios de Educación y por la Oficina Regional de UNESCO, en 1998, que se presentan en el siguiente cuadro. Con toda probabilidad, es difícil para los profesores enseñar en ambientes donde sus alumnos no tienen libros de 
texto, lápices o cuadernos. Pero el que tengan estos materiales -una condición indispensable y básica- no es necesariamente suficiente para que los alumnos aprendan, para que los maestros enseñen mejor o para que los alumnos aprendan a pensar por cuenta propia o a leer con gusto. Países que han llevado adelante reformas basadas en proporcionar estos insumos, en hacer talleres para profesores y en priorizar la atención a las escuelas con los más bajos rendimientos y en dar a las familias amplia libertad de elección sobre dónde educar a sus hijos promoviendo la matrícula en establecimientos privados, muestran en estas comparaciones internacionales resultados igualmente deplorables que sus vecinos.

Cuadro 14. Porcentaje de alumnos de tercero y cuarto grados de primaria que tienen materiales básicos de aprendizaje

\section{Libro de \\ Libro de}

Lenguaje Matemática Cuadernos Lápices Lenguaje Matemática Cuadernos Lápices Ciudades de más de 1 millón de habitantes.

\begin{tabular}{|c|c|c|c|c|c|c|c|c|}
\hline \multirow[b]{2}{*}{ Argentina } & \multicolumn{4}{|c|}{ Escuelas Públicas } & \multicolumn{4}{|c|}{ Escuelas Privadas } \\
\hline & $56 \%$ & $43 \%$ & $82 \%$ & $85 \%$ & $84 \%$ & $43 \%$ & $83 \%$ & $87 \%$ \\
\hline Bolivia & $76 \%$ & $57 \%$ & $82 \%$ & $90 \%$ & $90 \%$ & $77 \%$ & $83 \%$ & $90 \%$ \\
\hline Brasil & $84 \%$ & $82 \%$ & $97 \%$ & $96 \%$ & $76 \%$ & $67 \%$ & $99 \%$ & $96 \%$ \\
\hline Chile & $90 \%$ & $89 \%$ & $88 \%$ & $86 \%$ & $94 \%$ & $86 \%$ & $91 \%$ & $88 \%$ \\
\hline Colombia & $70 \%$ & $59 \%$ & $88 \%$ & $93 \%$ & $79 \%$ & $70 \%$ & $89 \%$ & $90 \%$ \\
\hline Cuba & $97 \%$ & $96 \%$ & $100 \%$ & $98 \%$ & $0 \%$ & $0 \%$ & $0 \%$ & $0 \%$ \\
\hline Honduras & $75 \%$ & $70 \%$ & $81 \%$ & $86 \%$ & $79 \%$ & $76 \%$ & $83 \%$ & $89 \%$ \\
\hline México & $96 \%$ & $91 \%$ & $95 \%$ & $94 \%$ & $100 \%$ & $95 \%$ & $99 \%$ & $97 \%$ \\
\hline $\begin{array}{l}\text { Perú } \\
\text { República }\end{array}$ & $55 \%$ & $65 \%$ & $80 \%$ & $84 \%$ & $84 \%$ & $77 \%$ & $84 \%$ & $83 \%$ \\
\hline Dominicana & $57 \%$ & $57 \%$ & $81 \%$ & $89 \%$ & $68 \%$ & $62 \%$ & $86 \%$ & $91 \%$ \\
\hline Venezuela & $71 \%$ & $73 \%$ & $83 \%$ & $80 \%$ & $81 \%$ & $60 \%$ & $91 \%$ & $89 \%$ \\
\hline \multicolumn{9}{|c|}{ Ciudades entre 2,500 y 1 millón de habitantes. } \\
\hline & \multicolumn{4}{|c|}{ Escuelas Públicas } & \multicolumn{3}{|c|}{ Escuelas Privadas } & \\
\hline Argentina & $58 \%$ & $44 \%$ & $85 \%$ & $88 \%$ & $73 \%$ & $38 \%$ & $89 \%$ & $87 \%$ \\
\hline Bolivia & $60 \%$ & $44 \%$ & $78 \%$ & $89 \%$ & $76 \%$ & $68 \%$ & $84 \%$ & $92 \%$ \\
\hline Brasil & $85 \%$ & $82 \%$ & $97 \%$ & $96 \%$ & $93 \%$ & $75 \%$ & $97 \%$ & $96 \%$ \\
\hline Chile & $93 \%$ & $88 \%$ & $90 \%$ & $88 \%$ & $95 \%$ & $86 \%$ & $93 \%$ & $90 \%$ \\
\hline Colombia & $67 \%$ & $54 \%$ & $85 \%$ & $91 \%$ & $84 \%$ & $78 \%$ & $94 \%$ & $93 \%$ \\
\hline Cuba & $97 \%$ & $94 \%$ & $100 \%$ & $99 \%$ & $0 \%$ & $0 \%$ & $0 \%$ & $0 \%$ \\
\hline Honduras & $76 \%$ & $78 \%$ & $80 \%$ & $87 \%$ & $68 \%$ & $64 \%$ & $90 \%$ & $87 \%$ \\
\hline México & $94 \%$ & $89 \%$ & $95 \%$ & $94 \%$ & $98 \%$ & $94 \%$ & $98 \%$ & $98 \%$ \\
\hline Paraguay & $76 \%$ & $72 \%$ & $85 \%$ & $88 \%$ & $87 \%$ & $78 \%$ & $91 \%$ & $93 \%$ \\
\hline Perú & $48 \%$ & $53 \%$ & $82 \%$ & $89 \%$ & $62 \%$ & $62 \%$ & $80 \%$ & $85 \%$ \\
\hline $\begin{array}{l}\text { Republica } \\
\text { Dominicana }\end{array}$ & $57 \%$ & $60 \%$ & $82 \%$ & $88 \%$ & $63 \%$ & $47 \%$ & $64 \%$ & $73 \%$ \\
\hline Venezuela & $76 \%$ & $80 \%$ & $91 \%$ & $91 \%$ & $84 \%$ & $81 \%$ & $86 \%$ & $90 \%$ \\
\hline
\end{tabular}

Ciudades de menos de 2,500 habitantes (zonas rurales).

\begin{tabular}{lllll} 
& & & \multicolumn{2}{c}{ Escuelas Pública } \\
Argentina & $59 \%$ & $51 \%$ & $86 \%$ & $88 \%$ \\
Bolivia & $45 \%$ & $36 \%$ & $84 \%$ & $92 \%$ \\
Brasil & $92 \%$ & $87 \%$ & $97 \%$ & $96 \%$ \\
Chile & $92 \%$ & $87 \%$ & $85 \%$ & $90 \%$ \\
Colombia & $70 \%$ & $67 \%$ & $88 \%$ & $94 \%$ \\
Cuba & $98 \%$ & $96 \%$ & $99 \%$ & $99 \%$
\end{tabular}




$\begin{array}{lllll}\text { Honduras } & 74 \% & 75 \% & 83 \% & 90 \% \\ \text { México } & 96 \% & 93 \% & 95 \% & 96 \% \\ \text { Paraguay } & 75 \% & 68 \% & 84 \% & 82 \% \\ \text { Perú } & 46 \% & 46 \% & 75 \% & 85 \% \\ \begin{array}{l}\text { República } \\ \text { Dominicana }\end{array} & 53 \% & 59 \% & 77 \% & 85 \% \\ \text { Venezuela } & 70 \% & 75 \% & 85 \% & 83 \%\end{array}$

Fuente: Cálculos propios sobre datos recogidos por UNESCO-OREALC en la encuesta administrada a una muestra de escuelas para evaluar la calidad de la educación. 1998.

Si todos los estudiantes más pobres, aquellos cuyos padres tienen más bajos niveles educativos, fuesen los que tienen más bajos niveles de rendimiento escolar, o los que expresan que no entienden las explicaciones de sus maestros, sería difícil dilucidar en qué medida estos bajos niveles de aprovechamiento reflejan características de la enseñanza que reciben, o diferencias en su capacidad de aprender. Sin embargo, existen estudiantes entre aquellos cuyos padres tienen más bajos niveles educativos, que entienden las explicaciones de sus maestros y que obtienen altos resultados en pruebas que reflejan los contenidos del currículo. Igualmente, los sistemáticamente más bajos resultados de los estudiantes latinoamericanos en relación a sus pares en otros países, sugieren que no son las diferencias entre los estudiantes, sino entre contextos de aprendizaje, las que explican estos bajos niveles de desempeño estudiantil. Entre los factores que cuya contribución es necesario investigar, están los niveles de exigencia del currículo, la calidad de los materiales educativos, los niveles de conocimiento de los profesores y las técnicas pedagógicas de los profesores y el clima instruccional en las escuelas y en el aula. En un reciente estudio en el que participé para evaluar el impacto de las políticas educativas en la calidad de la educación en Chile, encontré que el nivel de exigencia del currículo de lecto escritura era bajo, que los profesores tenían poca claridad y especificidad en sus objetivos instruccionales, y que su pedagogía para enseñar a leer no correspondía al conocimiento contemporáneo basado en el estudio de las formas más efectivas de realizar esta actividad.

En un reciente estudio sobre los factores asociados al éxito escolar de los estudiantes mexicanos de primera generación; es decir, de aquellos estudiantes de sexto grado cuyos padres y madres son analfabetos, encuentro que una proporción significativa de ellos tiene niveles de logro comparables a estudiantes cuyos padres tienen niveles educativos más altos. Si bien la proporción de estudiantes de primera generación que alcanza altos niveles de logro es menor que la de los demás estudiantes, es importante constatar que algunos lo hacen (16\% frente a $31 \%$ para el conjunto de los estudiantes) y sobre ello identificar qué factores explican los diferentes desempeños de estudiantes de primera generación. También encuentro que las prácticas docentes marcan una profunda diferencia entre aquellos estudiantes de primera generación que aprenden poco y los que aprenden a niveles comparables a estudiantes de origen social más alto, como muestra el cuadro 15. 
Cuadro 15. Cómo hablan de sus experiencias escolares los estudiantes cuyas madres son analfabetas (porcentajes)

\begin{tabular}{|c|c|c|c|}
\hline & \multicolumn{2}{|c|}{\begin{tabular}{|c|} 
Logro en una prueba de \\
español
\end{tabular}} & \multirow[t]{2}{*}{$\begin{array}{l}\text { Brecha bajo / alto } \\
\text { rendimiento }\end{array}$} \\
\hline & Bajo & Alto & \\
\hline $\begin{array}{l}\text { Aprendo mucho en la escuela } \\
\text { Mi maestra quiere que aprenda } \\
\text { mucho } \\
\text { Entiendo a mi maestra } \\
\text { Cuando no entiendo mi maestra } \\
\text { me ayuda } \\
\text { Mi maestra contesta mis } \\
\text { preguntas } \\
\text { Las reglas en el aula son claras } \\
\text { Peleamos mucho con mis } \\
\text { compañeros } \\
\text { Mi clase es agradable } \\
\text { La tarea es interesante } \\
\% \text { Niñas } \\
\% \text { Que trabajan } \\
\% \text { Que han repetido grado }\end{array}$ & $\begin{array}{l}60 \% \\
77 \% \\
43 \% \\
53 \% \\
\\
48 \% \\
39 \% \\
\\
13 \% \\
74 \% \\
82 \% \\
48 \% \\
26 \% \\
41 \%\end{array}$ & $\begin{array}{l}69 \% \\
90 \% \\
51 \% \\
64 \% \\
61 \% \\
52 \% \\
\\
9 \% \\
77 \% \\
90 \% \\
55 \% \\
19 \% \\
33 \%\end{array}$ & $\begin{array}{l}115.00 \% \\
116.88 \% \\
118.60 \% \\
120.75 \% \\
127.08 \% \\
133.33 \% \\
\\
69.23 \% \\
104.05 \% \\
109.76 \% \\
114.58 \% \\
73.08 \% \\
80.49 \%\end{array}$ \\
\hline
\end{tabular}

Basado en una prueba estandarizada de español y en cuestionarios administrados a una muestra nacional representativa de niños. Los alumnos de bajo rendimiento son aquellos que contestan nueve preguntas 0 menos correctamente en la prueba de 26 items, quienes representan la mitad de los 5559 estudiantes cuyas madres son analfabetas. Los alumnos de alto rendimiento son aquellos que contestaron la mitad o más de las preguntas de la prueba correctamente, quienes representan $16 \%$ de los alumnos cuyas madres son analfabetas. Basado en Reimers, Fernando. When teachers teach well understanding the academic success of first generation students. Trabajo presentado en la 46 conferencia anual de la Comparative and International Education Society. Orlando, Florida, 6-9 March 2002.

En este estudio encuentro que la buena enseñanza logra mayores resultados con aquellos estudiantes cuyos padres tienen bajos niveles educativos. Encuentro también que la buena enseñanza no es sólo el resultado de lo que hagan los maestros, sino que resulta de la confluencia de varios factores que como un sistema facilita o no que los maestros enseñen bien. Estos factores incluyen la disponibilidad de materiales pedagógicos, la cultura de la escuela, el énfasis del director del centro en el aprendizaje de los chicos, y las expectativas del director y docentes sobre las capacidades de los estudiantes.

Los estudiantes cuyos padres tienen más bajos niveles educativos, sin embargo, tienden a estar concentrados en centros en donde no existen todos los elementos de este sistema simple. Como resultado, enseñar bien es más difícil y menos frecuente. Esta es la explicación del alto fracaso educativo de los hijos de los pobres.

La falta de acceso a materiales básicos de lectura es confirmada por las respuestas de los profesores a la pregunta de si alcanzan los textos para cada niño, a la cual 2 de cada cinco maestros dice que no.

Cuadro 16. Respuestas de los maestros a la pregunta textos?, en Colombia, en 1998 


\begin{tabular}{|l|c|c|}
\hline & No & Si \\
Mega-Público & $34.5 \%$ & $65.5 \%$ \\
Mega-Privado & $23.5 \%$ & $76.5 \%$ \\
Urbano-Público & $45.7 \%$ & $54.3 \%$ \\
Urbano-Privado & $32.1 \%$ & $67.9 \%$ \\
Rural & $49.3 \%$ & $50.7 \%$ \\
Total & $41.4 \%$ & $58.6 \%$ \\
\hline
\end{tabular}

Fuente: Cálculos propios de datos procedentes de la encuesta administrada por el Ministerio de Educación y la Oficina Regional de UNESCO para América Latina y el Caribe (Laboratorio Latinoamericano de la Calidad de la Educación). Estrato Mega Ciudad se refiere a ciudades con más de 1 millón de habitantes. Urbano se refiere a ciudades de menos de 1 millón de habitantes.

La carencia de materiales básicos de aprendizaje impide la práctica regular de la lectura. Al preguntar a los estudiantes qué habían leído la semana anterior a la encuesta, sólo 3 de cada cinco indicaron que habían leído un libro, casi la mitad que habían leído comics y dos de cada cinco que había leído periódicos. Leer a otras personas o en voz alta es una práctica infrecuente. Casi $15 \%$ dijeron que no habían leído nada.

Cuadro 17. Porcentaje de niños que indica que realizó diversos tipos de lectura la semana anterior a la encuesta, en Colombia, en 1998

\begin{tabular}{|c|c|c|c|c|c|c|c|}
\hline & Libro & Comic & eriódic & $\begin{array}{l}\text { Leyó a } \\
\text { ermanos }\end{array}$ & $\begin{array}{l}\text { Leyó en } \\
\text { voz alta }\end{array}$ & $\begin{array}{c}\text { Leyó } \\
\text { otra } \\
\text { cosa }\end{array}$ & No leyó \\
\hline Mega-Público & $63 \%$ & $46 \%$ & $36 \%$ & $33 \%$ & $39 \%$ & $31 \%$ & $16 \%$ \\
\hline Mega-Privado & $64 \%$ & $45 \%$ & $32 \%$ & $27 \%$ & $33 \%$ & $30 \%$ & $14 \%$ \\
\hline Urbano-Público & $65 \%$ & $46 \%$ & $43 \%$ & $39 \%$ & $45 \%$ & $35 \%$ & $14 \%$ \\
\hline Urbano-Privado & $63 \%$ & $53 \%$ & $41 \%$ & $33 \%$ & $36 \%$ & $35 \%$ & $15 \%$ \\
\hline Rural & $68 \%$ & $38 \%$ & $44 \%$ & $38 \%$ & $43 \%$ & $38 \%$ & $14 \%$ \\
\hline Total & $65 \%$ & $45 \%$ & $41 \%$ & $36 \%$ & $41 \%$ & $35 \%$ & $14 \%$ \\
\hline
\end{tabular}

Fuente: Cálculos propios de datos procedentes de la encuesta administrada por el Ministerio de Educación y la Oficina Regional de UNESCO para América Latina y el Caribe (Laboratorio Latinoamericano de la Calidad de la Educación). Estrato Mega Ciudad se refiere a ciudades con más de 1 millón de habitantes. Urbano se refiere a ciudades de menos de 1 millón de habitantes.

Las limitadas oportunidades para leer se relacionan también con la carencia de materiales de lectura en los hogares de los niños y con la infrecuente práctica de que los padres lean a los niños. En casi dos de cada cinco hogares no hay libros para leer, y en 4 de cada 5 hogares rurales y en 3 de cada 5 hogares de alumnos de escuelas publicas hay menos de 10 libros. Uno de cada cinco niños sus padres no les leían casi nunca, y a otro de cada cinco niños les leían infrecuentemente, menos de 1 vez al mes. Sólo una tercera parte de los niños tienen padres que les leían casi diariamente cuando pequeños. 
Cuadro 18. Cantidad de libros que los estudiantes indican que hay en sus casas en Colombia, en 1998

$\begin{array}{lcccc} & \text { No hay } & \text { Menos de } \mathbf{1 0} & \text { De } \mathbf{1 0} \text { a } \mathbf{5 0} & \text { Más de } \mathbf{5 0} \\ \text { Mega-Público } & 7.9 \% & 38.8 \% & 40.7 \% & 12.6 \% \\ \text { Mega-Privado } & 2.6 \% & 26.8 \% & 43.5 \% & 27.1 \% \\ \text { Urbano-Público } & 20.2 \% & 44.8 \% & 25.4 \% & 9.6 \% \\ \text { Urbano-Privado } & 3.5 \% & 30.6 \% & 40.7 \% & 25.2 \% \\ \text { Rural } & 28.7 \% & 49.8 \% & 17.6 \% & 3.9 \% \\ \text { Total } & 17.4 \% & 41.8 \% & 28.7 \% & 12.2 \%\end{array}$

Fuente: Cálculos propios de datos procedentes de la encuesta administrada por el Ministerio de Educación y la Oficina Regional de UNESCO para América Latina y el Caribe (Laboratorio Latinoamericano de la Calidad de la Educación). Estrato Mega Ciudad se refiere a ciudades con más de 1 millón de habitantes. Urbano se refiere a ciudades de menos de 1 millón de habitantes.

Cuadro 19. Respuesta de los padres a la pregunta de si acostumbraba a leerle al niño cuando pequeño, en Colombia, en 1998.

\begin{tabular}{l|ccccc} 
& Casi diario & $\begin{array}{c}\text { Más de 1 vez } \\
\text { al mes }\end{array}$ & $\begin{array}{c}\text { 1 vez al mes } \\
\text { 2 a 3 veces } \\
\text { al año }\end{array}$ & Casi nunca \\
\hline Mega-Público & $19.1 \%$ & $30.6 \%$ & $10.7 \%$ & $17.7 \%$ & $21.9 \%$ \\
Mega-Privado & $21.9 \%$ & $37.1 \%$ & $11.2 \%$ & $12.8 \%$ & $17.0 \%$ \\
Urbano-Público & $29.6 \%$ & $29.2 \%$ & $10.7 \%$ & $13.8 \%$ & $16.8 \%$ \\
Urbano-Privado & $34.2 \%$ & $36.1 \%$ & $9.1 \%$ & $10.6 \%$ & $10.1 \%$ \\
Rural & $26.0 \%$ & $25.8 \%$ & $13.4 \%$ & $12.7 \%$ & $22.2 \%$ \\
& $26.9 \%$ & $30.1 \%$ & $11.4 \%$ & $13.3 \%$ & $18.2 \%$
\end{tabular}

Fuente: Cálculos propios de datos procedentes de la encuesta administrada por el Ministerio de Educación y la Oficina Regional de UNESCO para América Latina y el Caribe (Laboratorio Latinoamericano de la Calidad de la Educación). Estrato Mega Ciudad se refiere a ciudades con más de 1 millón de habitantes. Urbano se refiere a ciudades de menos de 1 millón de habitantes.

En síntesis, la pedagogía que utilizan las maestras en las escuelas primarias no es efectiva para que una tercera parte de los estudiantes comprendan. La mayoría de los estudiantes no encuentran estimulantes las lecturas que hacen sus profesores. Esto hace que los ambientes escolares sean débiles para promover el interés por la lectura y el desarrollo de habilidades lectoras efectivas. Esto se ve agravado por la carencia de materiales básicos de lectura en el caso de algunos estudiantes, y por los pocos materiales de lectura que existen en los hogares de muchos estudiantes. Son pocos los estudiantes cuyos padres acostumbraban a leerles cuando pequeños.

\section{El clima social y afectivo en la escuela no enseña a respetar los derechos fundamentales de los demás y a confiar en ellos}

Las débiles competencias pedagógicas de los profesores se reflejan no sólo en su incapacidad para desarrollar competencias lectoras en todos los estudiantes, sino en la incapacidad de crear climas instruccionales respetuosos donde los estudiantes adquieran habilidades interpersonales fundamentales para la convivencia democrática. Mencionaba anteriormente, que una de las disposiciones esenciales para la vida en democracia es la capacidad de confiar en los demás. Maestros que establecen un clima instruccional respetuoso, que respetan a sus estudiantes y que les enseñan a respetarse unos a otros, contribuyen a que los estudiantes aprendan a confiar en los demás. En la encuesta 
mencionada anteriormente, por el contrario, un porcentaje elevado de los estudiantes indicaron que no confiaban en sus profesores.

Cuadro 20. Porcentaje de estudiantes que indican que tiene confianza en el maestro, en Colombia, en 1998

Sí

Mega-Público
Mega-Privado
Urbano-Público
Urbano-Privado
Rural
Total

$24.2 \%$
$27.0 \%$
$29.7 \%$
$27.2 \%$
$32.0 \%$
$29.1 \%$

A veces

$38.5 \%$
$39.5 \%$
$38.2 \%$
$41.1 \%$
$39.3 \%$
$39.1 \%$

No

$\begin{array}{ll}37.2 \% & 100.0 \% \\ 33.5 \% & 100.0 \% \\ 32.1 \% & 100.0 \% \\ 31.7 \% & 100.0 \% \\ 28.8 \% & 100.0 \% \\ 31.9 \% & 100.0 \%\end{array}$

Fuente: Cálculos propios de datos procedentes de la encuesta administrada por el Ministerio de Educación y la Oficina Regional de UNESCO para América Latina y el Caribe (Laboratorio Latinoamericano de la Calidad de la Educación). Estrato Mega Ciudad se refiere a ciudades con más de 1 millón de habitantes. Urbano se refiere a ciudades de menos de 1 millón de habitantes.

Igualmente, al preguntar a los estudiantes por sus relaciones con los compañeros, una gran mayoría indicó que los compañeros molestan, y una tercera parte afirmó que tienen peleas constantes con sus compañeros. A pesar del deficiente clima social de las escuelas, la mayoría de los estudiantes señala que tienen buenas amistades entre algunos de sus compañeros.

Cuadro 21. Porcentaje de estudiantes que indican que sus compañeros molestan, que tiene peleas constantes y que tienen buenas amistades en la escuela, en Colombia, en 1998

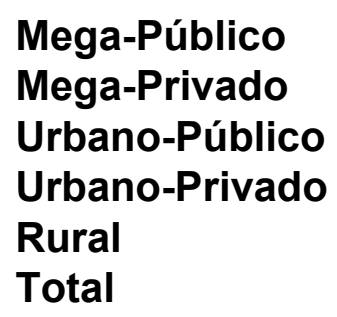

Fuente: Cálculos propios de datos procedentes de la encuesta administrada por el Ministerio de Educación y la Oficina Regional de UNESCO para América Latina y el Caribe (Laboratorio Latinoamericano de la Calidad de la Educación). Estrato Mega Ciudad se refiere a ciudades con más de 1 millón de habitantes. Urbano se refiere a ciudades de menos de 1 millón de habitantes.

Al preguntarles qué es lo que menos les gusta de la escuela, uno de cada cinco estudiantes indicó que los compañeros, y una proporción semejante señaló que los maestros.

$\begin{array}{ccc}\text { Los compañeros molestan } & \text { Peleas constantes } & \text { Buenas amistades } \\ 94 \% & 30 \% & 90 \% \\ 89 \% & 20 \% & 94 \% \\ 90 \% & 36 \% & 92 \% \\ 90 \% & 28 \% & 97 \% \\ 86 \% & 31 \% & 94 \% \\ 89 \% & 31 \% & 93 \%\end{array}$


Cuadro 22. Respuesta de los estudiantes a la pregunta de qué es lo que más les molesta de la escuela, en Colombia, en 1998

\section{Mega-Público \\ Mega-Privado \\ Urbano-Público \\ Urbano-Privado \\ Rural}

Total

\section{Compañeros}

$24 \%$

$18 \%$

$33 \%$

$20 \%$

$26 \%$

$26 \%$

Director
$8 \%$
$9 \%$
$9 \%$
$11 \%$
$8 \%$
$9 \%$

Aula

$11 \%$

$14 \%$

$17 \%$

$15 \%$

$20 \%$

$17 \%$

$\begin{array}{cc}\text { Patio } & \text { Otros } \\ 25 \% & 9 \% \\ 25 \% & 10 \% \\ 16 \% & 6 \% \\ 18 \% & 11 \% \\ 25 \% & 6 \% \\ 21 \% & 7 \%\end{array}$

Fuente: Cálculos propios de datos procedentes de la encuesta administrada por el Ministerio de Educación y la Oficina Regional de UNESCO para América Latina y el Caribe (Laboratorio Latinoamericano de la Calidad de la Educación). Estrato Mega Ciudad se refiere a ciudades con más de 1 millón de habitantes. Urbano se refiere a ciudades de menos de 1 millón de habitantes.

Quienes pelean constantemente con sus compañeros tienen una probabilidad $50 \%$ superior de mencionar que lo que menos les gusta de la escuela son sus compañeros que quienes no tienen peleas constantes. Mientras que entre quienes pelean constantemente el $34 \%$ dice que sus compañeros son lo que menos les gusta de la escuela, entre quienes no pelean constantemente el $22 \%$ dice que lo que menos les gusta son sus compañeros.

Igualmente, los alumnos que dicen no confiar en sus maestros tienen una probabilidad $40 \%$ más alta de señalar que lo que menos les gusta de la escuela son los maestros que aquellos que sí confían en sus maestros. Mientras que entre los que dicen que sí confían en sus maestros el $16 \%$ señala que los maestros es lo que menos les gusta de la escuela, entre quienes dicen que a veces confían en sus maestros el $20 \%$ señalan a los maestros como lo que menos les gusta de la escuela, y entre quienes dicen que no confían en sus maestros el $23 \%$ señalan a los maestros como lo que menos les gusta de la escuela. En cualquiera de los casos es sintomático que uno de cada cinco estudiantes señale que son sus maestros lo que menos les gusta de su escuela.

Al preguntar a los padres cuáles son los principales problemas de la escuela, una tercera parte señalan robos, uno de cada cinco se refieren a violencia entre alumnos y una tercera parte se refieren a falta de disciplina. Todos estos problemas coinciden en caracterizar un clima social y afectivo deficiente, de falta de respeto por los demás, de poca capacidad de resolver diferencias en forma productiva y pacífica.

Cuadro 23. Respuestas de los padres a la pregunta de cuáles son los problemas más graves de la escuela, en Colombia, en 1998

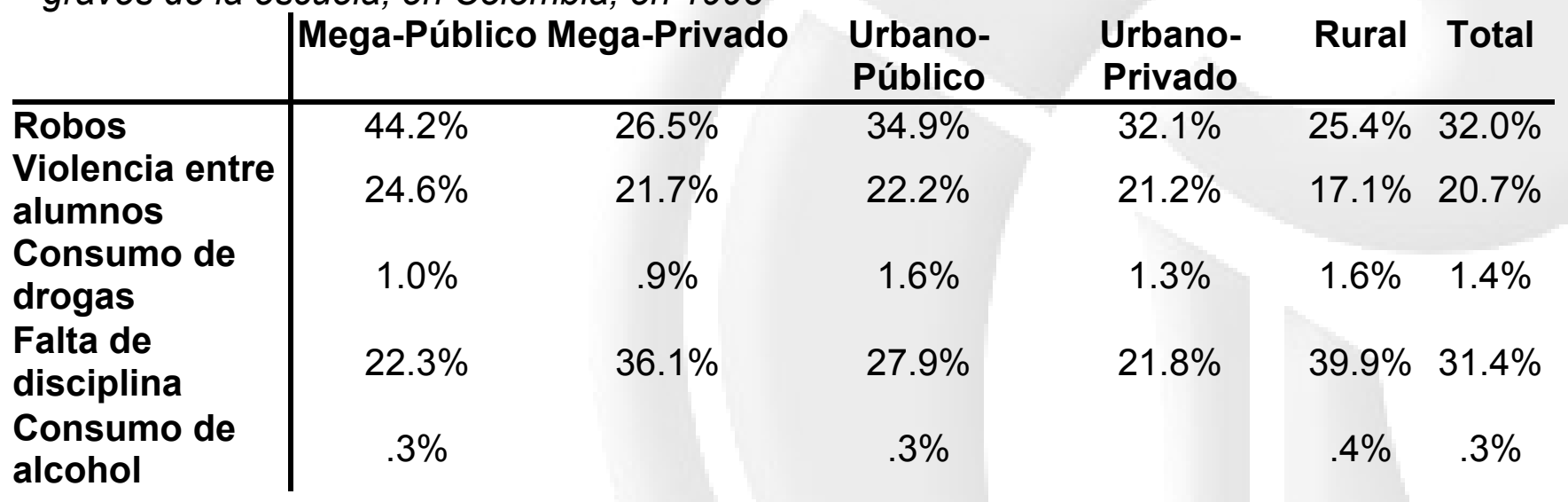




\section{Alumnos sin interés en estudios \\ Profesores abusan de alumnos Profesores desmotivados Poca consideración con padres}

$\begin{array}{lccccc}4.7 \% & 7.4 \% & 9.9 \% & 14.7 \% & 11.1 \% & 9.7 \% \\ .3 \% & .9 \% & 1.1 \% & 1.3 \% & .5 \% & .8 \% \\ 1.3 \% & 3.0 \% & 1.3 \% & 1.3 \% & 3.1 \% & 2.0 \% \\ 1.3 \% & 3.5 \% & .8 \% & 6.4 \% & .9 \% & 1.6 \%\end{array}$

Fuente: Cálculos propios de datos procedentes de la encuesta administrada por el Ministerio de Educación y la Oficina Regional de UNESCO para América Latina y el Caribe (Laboratorio Latinoamericano de la Calidad de la Educación). Estrato Mega Ciudad se refiere a ciudades con más de 1 millón de habitantes. Urbano se refiere a ciudades de menos de 1 millón de habitantes.

Estas deficiencias en el clima social que la escuela brinda a los alumnos se relacionan con el clima social que caracteriza las relaciones entre maestras y directores. Una proporción importante de las escuelas no funciona como organizaciones colegiadas integradas. Así, uno de cada cuatro maestros no considera que sus colegas apoyan sus iniciativas, uno de cada cinco no siente que el director de la escuela reconoce su trabajo y una tercera parte indica que no hay comunicación entre colegas sobre tareas pedagógicas. Uno de cada cuatro considera que no son claros los roles entre el director y los maestros y un $17 \%$ se siente inseguro en la escuela.

Cuadro 24. Caracterización que hacen los maestros del clima organizacional en la escuela en Colombia, en 1998

\begin{tabular}{l|ccccc} 
& $\begin{array}{c}\text { Mis colegas } \\
\text { apoyan mis } \\
\text { iniciativas }\end{array}$ & $\begin{array}{c}\text { El director } \\
\text { reconoce mi } \\
\text { trabajo }\end{array}$ & $\begin{array}{c}\text { Mis colegas } \\
\text { me consultan } \\
\text { sobre el } \\
\text { trabajo }\end{array}$ & $\begin{array}{c}\text { Falta } \\
\text { definición de } \\
\text { roles entre } \\
\text { dirección y } \\
\text { maestros }\end{array}$ & $\begin{array}{c}\text { La } \\
\text { inseguridad } \\
\text { me poncuela } \\
\text { nervioso }\end{array}$ \\
\hline $\begin{array}{l}\text { Mega-Público } \\
\text { Mega-Privado }\end{array}$ & $68.20 \%$ & $76.50 \%$ & $62.20 \%$ & $21.50 \%$ & $22.30 \%$ \\
$\begin{array}{l}\text { Urbano- } \\
\text { Público }\end{array}$ & $77.50 \%$ & $83.00 \%$ & $73.50 \%$ & $22.90 \%$ & $8.40 \%$ \\
$\begin{array}{l}\text { Urbano- } \\
\text { Privado }\end{array}$ & $74.00 \%$ & $81.90 \%$ & $65.90 \%$ & $31.20 \%$ & $22.30 \%$ \\
$\begin{array}{l}\text { Rural } \\
\text { Total }\end{array}$ & $73.90 \%$ & $82.10 \%$ & $66.60 \%$ & $20.50 \%$ & $6.60 \%$ \\
\hline
\end{tabular}

Fuente: Cálculos propios de datos procedentes de la encuesta administrada por el Ministerio de Educación y la Oficina Regional de UNESCO para América Latina y el Caribe (Laboratorio Latinoamericano de la Calidad de la Educación). Estrato Mega Ciudad se refiere a ciudades con más de 1 millón de habitantes. Urbano se refiere a ciudades de menos de 1 millón de habitantes.

En síntesis, el clima en una proporción importante de escuelas en Colombia es, a los ojos de estudiantes y maestros, deficiente desde el punto de vista de la convivencia. No hay respeto y hay demasiada violencia y malas relaciones interpersonales entre alumnos. Los maestros y directores, por su parte, tampoco tienen entre sí relaciones interpersonales y colegiadas respetuosas para permitir que el trabajo en equipo sea productivo. Como consecuencia, es improbable que en escuelas, con estas deficiencias en el clima social, 
puedan desarrollarse habilidades y disposiciones fundamentales para vivir en democracia: la capacidad de respetar a otras personas, la posibilidad de valorar las diferencias como una fortaleza, la habilidad para negociar diferencias de forma pacífica y productiva. Al mismo tiempo, el deficiente clima social de muchas escuelas condena a los profesores a tratar de enfrentar solos los complejos desafíos de enseñar a niveles de excelencia a estudiantes, en medio de carencias de condiciones materiales básicas y de limitaciones en sus propias capacidades para hacerlo.

\section{Fortalecer las competencias pedagógicas de los maestros y desarrollar fuertes culturas escolares donde el respeto a los demás y el aprecio por la libertad sean valores que se reflejen en las relaciones cotidianas}

No hay solución simple a los complejos desafíos de deficiencias pedagógicas y organizacionales descritas en este trabajo para apoyar el que los estudiantes en Colombia aprendan en la escuela en profundidad habilidades y disposiciones que les permitan ejercer ser ciudadanos responsables y vivir en paz. ¿Cómo pueden aprender a confiar en los demás, estudiantes que no sienten que pueden confiar en sus maestros? ¿En sus compañeros? ¿Y que describen que sus escuelas son ambientes violentos? ¿Cómo hacer que no deserten de la escuela estudiantes que encuentran poco claras las explicaciones de sus profesores, para quienes lo más desagradable de la escuela son compañeros y profesores? ¿Cómo hacer que aprendan a leer a niveles sofisticados estudiantes cuyos profesores no leen de forma estimulante, con insuficientes materiales de lectura, en cuyos hogares no hay costumbre de leer ni materiales de lectura?

Intentar resolver estos problemas requiere el esfuerzo conjunto y coordinado de diversos grupos, y la colaboración efectiva a nivel local y en niveles superiores de administración. Es importante que las escuelas comiencen a funcionar como equipos de trabajo, donde maestros y directores colaboren, se comuniquen efectivamente, se respeten, y modelen para sus estudiantes un clima democrático y de gestión grupal eficaz. Para que los maestros puedan hacer esto, probablemente necesiten apoyo de otras instancias, apoyo e incentivos para desarrollar competencias pedagógicas y de trabajo en grupo, materiales pedagógicos para poder facilitar su tarea, esfuerzos y una relación con niveles superiores de administración que comuniquen claras expectativas y respeto hacia la profesión docente. Sólo los maestros que experimenten un trato respetuoso de sus colegas y superiores podrán a su vez aprender a respetar a sus colegas y estudiantes; sólo quienes experimenten relaciones democráticas podrán construir climas democráticos en sus escuelas; sólo quienes comprendan que sobre ellos hay altas expectativas y esperanza podrán a su vez tener sobre sus estudiantes altas expectativas y esperanzas.

El cambio, de aquellos aspectos más importantes en el proceso educativo; es decir, de las prácticas que constituyen la cotidianeidad de la escuela, tiene sólo vínculos muy tenues con las decisiones de los planificadores educativos, y depende mucho más de las decisiones, expectativas y de la práctica de múltiples agentes en la escuela y alrededor de ella, que son independientes de los planificadores y pueden ser igualmente transformadas de forma significativa en el curso de su implantación.

La práctica educativa tiene mucho más que ver con la cultura de la escuela, con la forma en que maestros definen su rol, con las expectativas recíprocas entre maestros, directivos escolares, en ocasiones miembros de la comunidad, que con la práctica de los planificadores educativos tradicionales. Los cambios en educación ocurren como resultado de la construcción compartida entre un grupo grande de interlocutores, por lo que es necesario construir espacios explícitamente de articulación de este diálogo para 
poder examinar las consecuencias de las prácticas actuales y considerar posibles prácticas alternativas ${ }^{49}$.

La mejora de las condiciones de vida en América Latina descansa en parte en la profundización de la democracia, en la construcción de comunidad, del tejido social, en el fortalecimiento de las capacidades asociativas y de la confianza interpersonal, así como en el aumento de las competencias individuales que hagan a las personas más eficaces y productivas. Las políticas educativas consistentes con ese propósito tienen que ser necesariamente incluyentes, no pueden continuar manteniendo sistemas de apartheid educativo donde muchos aprenden muy poco. Además, se debe plantear una visión amplia del tipo de competencias necesarias para construir comunidades y sociedades democráticas. Hay competencias individuales necesarias para esto, como el desarrollar habilidades interpersonales en resolución de conflictos o el desarrollo del pensamiento moral. Hay experiencias que tienen que ser integradas en el currículo si la escuela ha de servir a formar ciudadanos que puedan ejercer prácticas democráticas en su vida cotidiana. Un proyecto incluyente, orientado a la equidad tiene más probabilidades de mejorar las condiciones de vida de todas las personas.

Quienes entienden que una función importante de la escuela es la de brindar igualdad de oportunidades educativas a todos los niños, reconocen que esto significa más que brindar igual oportunidad de matricularse en primer grado ${ }^{50}$. Es esencial apoyar con educación de calidad a los estudiantes a lo largo de todas sus trayectorias educativas ${ }^{51}$.

Para revitalizar la cultura de la escuela, de forma que las maestras se sientan apoyadas por sus colegas, y para que todas trabajen en búsqueda de un propósito común, es necesario iniciar trabajo en equipo que se apoye en métodos de investigación acción, donde equipos de maestras se reúnan a discutir los desafíos que confrontan sus estudiantes, a identificar sus causas y a establecer programas escolares de cambio y programas de autoformación. En la ultima década se ha experimentado en América Latina, con múltiples programas piloto orientados a que los equipos docentes lleven a cabo formas diversas de diagnóstico y planeación de este tipo. El desafió en muchos casos es orientar estos esfuerzos de gestión escolar hacia el desarrollo de pedagogías más efectivas.

Es necesario entender el desarrollo profesional de los maestros como un proceso de largo plazo que resulta de la preparación académica, de las experiencias acumuladas a través de los años, y de examinar sistemáticamente sus prácticas en el aula. Este proceso de largo plazo incluye oportunidades y experiencias que se planifican sistemáticamente.

El desarrollo profesional de los docentes puede considerarse desde una perspectiva tradicional o contemporánea. La perspectiva contemporánea concibe al desarrollo profesional basado en una perspectiva constructivista, como proceso de largo plazo, donde los maestros son percibidos como estudiantes activos, y donde el apoyo y seguimiento sistemáticos son indispensables. El desarrollo profesional está integrado con actividades diarias y relacionado con esfuerzos más amplios de reforma escolar. Esta

\footnotetext{
${ }^{49}$ Ver REIMERS, Fernando y McGINN, Noel, Diálogo Informado. México. Centro de Estudios Educativos y Asociación de Universidades Encomendadas a la Compañía de Jesús en América Latina, 2000.

${ }_{50}$ Esta noción de que la igualdad de oportunidades equivale a la igualdad en la oportunidad de acceso inicial a la escuela domina el ideario público sobre educación en la región.

${ }^{51}$ Para una discusión detallada de las políticas orientadas a fortalecer la equidad, véase REIMERS, F. (Ed.) Unequal Schools, Unequal Chances. The challenges to equal opportunity in the Americas. Cambridge, MA., Harvard University Press, Publicado en español como Distintas escuelas. Diferentes oportunidades. Madrid. Editorial Arco/La Muralla, 2002.
} 
perspectiva entiende a los maestros como investigadores con capacidad de reflexionar sobre sus prácticas. La perspectiva constructivista entiende al conocimiento como continuamente en formación y como el resultado del trabajo conjunto entre docentes y aprendices. En esta perspectiva, el desarrollo profesional es un proceso de colaboración en equipos y existe una gran variedad de modelos para promoverlo. El contexto determina cuál es la "combinación" más efectiva.

En comparación, la perspectiva tradicional está basada en un modelo de transmisión del conocimiento, las oportunidades de formación son de corto plazo y están desconectadas. En esta perspectiva, los maestros son pasivos e interpretan el conocimiento generado por otros y generalmente hay poco apoyo o seguimiento. En esta perspectiva el desarrollo profesional está desconectado de la práctica cotidiana, no se concibe como parte de la reforma educativa. Esta perspectiva entiende a los maestros como consumidores e interpretes de las investigaciones y teorías de otros

Características del desarrollo profesional de los maestros. En esta perspectiva el desarrollo profesional puede ser un proceso individual o de colaboración. El contexto raramente se toma en cuenta para definir cuál es la modalidad más adecuada de formación.

¿Cuáles son las competencias que necesitan desarrollar los maestros?

- Materias a enseñar

- Conocimiento de pedagogía como materia

- Conocimiento de la práctica pedagógica

- $\quad$ Conocimiento del contexto de los estudiantes

- Psicología del desarrollo humano

- Destrezas para relacionar la teoría con la práctica

- Destrezas clínicas (preguntar, escuchar, etc.)

- Destrezas para usar y enseñar sobre la tecnología

- Destrezas de evaluación y asesoría

- $\quad$ Conocimiento de la escuela, su comunidad y su sociedad

- Conciencia política y de justicia social

Hay varios modelos para el desarrollo profesional de los maestros, los cuales pueden agruparse en dos grandes categorías: aquellos que requieren colaboración entre instituciones, y aquellos que se basan en la acción en grupos pequeños, aquellos que requieren.

Modelos que requieren colaboración entre instituciones

- Escuelas de desarrollo profesional

- Otras colaboraciones entre escuelas y universidades

- Colaboración entre universidades, escuelas y otras instituciones

- Redes de escuelas

- Redes de maestros 
Educación a distancia

Modelos individuales o de pequeños grupos

- Supervisión: tradicional y clínica

- Asesoría de las actividades de los estudiantes

Seminarios, cursos, talleres, etc.

- Estudios de caso

- Desarrollo dirigido individualmente

- Desarrollo con colegas

- Observación de prácticas excelentes

- Participación en roles nuevos

- Uso de narrativas

- Uso de tutores o mentores

- Modelo generacional

- Modelo de desarrollo de destrezas

- Modelos de reflexión

- Modelos basados en proyectos

- Portafolios

- Investigación acción

Es importante que en estas tareas de apoyo a la formación de equipos de docentes en la escuela, el trabajo de los docentes se centre tanto en las cuestiones de técnica pedagógica, de cómo enseñar mejor y en profundidad las habilidades fundamentales como la lecto escritura, como en conversaciones más profundas sobre los valores que debe reflejar la escuela y sobre cómo preparar a los estudiantes para vivir en democracia. Es conveniente que los maestros discutan en qué forma la organización de la escuela y las formas de relación entre profesores y estudiantes son en sí mismas poderosas lecciones morales. Es difícil enseñar a vivir en democracia si las relaciones en la escuela son autoritarias e irrespetuosas. El desarrollo de competencias para el respeto a la legalidad, a la vida de los demás, a las instituciones, requiere atención a tres áreas ínterrelacionadas: la construcción de ambientes democráticos en la escuela, la inclusión en el currículo de atención a los procesos para el desarrollo de competencias para la convivencia $y$, finalmente, la atención a la relación de los equipos docentes con comunidades y con administradores y supervisores. Es insuficiente tratar de desarrollar competencias para la convivencia en una asignatura específica, si éstas contradicen la cultura más amplia de la escuela. No tendrán efecto espacios aislados en el programa de estudio para desarrollar sensibilidad ciudadana si éstos están inmersos en culturas escolares autoritarias e irrespetuosas que contradigan en su práctica los mensajes de estas asignaturas. Es necesario asegurar que las disposiciones y destrezas para la vida en democracia se desarrollen simultáneamente en el currículo más explícito -en las asignaturas-, en el currículo más profundo de la escuela -reflejado en la forma en que se relacionan alumnos entre sí, alumnos con profesores-y en la forma en que los equipos colegiados a su vez se relacionan con los padres y la comunidad escolar y con los supervisores escolares y otras instituciones de la localidad.

Los grupos de profesores en las escuelas que conversen sobre la forma de mejorar su práctica podrían discutir cómo preparar a los estudiantes para la vida, ayudarles a desarrollar destrezas que permitan desarrollar la capacidad de pensar por cuenta propia; desarrollar el aprecio por la libertad y la capacidad para ejercerla con responsabilidad; 
desarrollar la capacidad de apreciar la diversidad y las diferencias entre las personas; desarrollar la capacidad de asociarse con los demás; desarrollar la capacidad de valorar los derechos fundamentales de todas las personas; desarrollar la capacidad de vivir saludablemente y de preservar el equilibrio ecológico y desarrollar capacidades sofisticadas de comunicación y de aprender continuamente. El desarrollo de estas capacidades es esencial a un proyecto de sociedad orientado a la libertad, a la democracia y a la justicia. En medio de una de las recesiones económicas más severas de las últimas décadas, es conveniente que la discusión sobre los propósitos de la educación no se reduzca demasiado al desarrollo de competencias con rentabilidad en el mercado laboral. Es conveniente insistir en que el aprender es un bien en sí mismo y que reduce una forma de pobreza, aun si no se traduce en mejoras materiales en las condiciones de vida de las personas.

El currículo de las escuelas debe desarrollar competencias específicas para la vida en democracia. Como resultado de la pesada herencia autoritaria de la región, la mayoría de las escuelas de la región son mudas en relación a qué hace falta para vivir en democracia. La mayoría ni siquiera enseña a los estudiantes cuáles son los derechos humanos contenidos en la Declaración Universal, adoptada hace más de medio siglo por las naciones del mundo en la creación de Naciones Unidas. Como resultado, las escuelas producen analfabetos cívicos. Entre las competencias más importantes que las escuelas deberán desarrollar son las de poder negociar diferencias con otros, las de saber apreciar la diversidad como fortaleza, las de tener repertorios efectivos de comunicación interpersonal y grupal y de logros de acuerdos. Los programas educativos deben explícitamente incorporar contenidos que desarrollen habilidades, disposiciones y valores que prefieran la resolución pacífica de conflictos a las alternativas, que reconozcan y valoren la diversidad de puntos de vista, que prefieran las formas democráticas de organización a las formas autoritarias, que permitan construir una cultura cívica desde la escuela donde el recurso a la argumentación razonada sobre la base de evidencia sea preferido como forma de lograr acuerdos y de persuadir, a la imposición de dogmas de fe por unos grupos sobre otros.

Es factible apoyar a las maestras en la tarea de enseñar a los niños a leer y de desarrollar competencias cívicas. En pequeña escala, existen experimentos en la región y fuera de ella que permitirían a cada maestra conocer cómo desarrollar una clase efectiva en cada uno de estos temas. Hay programas que han demostrado ser efectivos desarrollando habilidades de lecto escritura, currículo sobre derechos humanos, programas que promueven la lectura crítica de la prensa en comunidades marginadas. Una primera tarea aun por hacer es hacer un inventario de estos programas, catalogarlos y hacer este catálogo accesible a quien tenga interés. Una segunda es promover el desarrollo de materiales impresos de alta calidad que permitan apoyar a las maestras al implementar estos programas en el aula.

Hay en Colombia una rica experiencia con buenos materiales para la promoción de la vida democrática, las actitudes cívicas, la discusión de dilemas éticos, desarrollados por fundaciones, universidades y por algunas Secretarías de educación, como la Secretaría de Educación de Bogotá en años recientes. Algunos de estos materiales incluyen los publicados en la serie de revistas de la Fundación Restrepo Barco sobre liderazgo, participación, enfoque de género, y desarrollo organizacional ${ }^{52}$. La compañía de Jesús ha

\footnotetext{
52 Entre otras: El liderazgo y la comunicación efectiva: punto de partida para una óptima gestión administrativa, por Gloria Cajiao de Pérez y Yolanda Sierra Castellanos. F.R.B., UNICEF Colombia, I.C.B.F., Bogotá, 2001; La participación está en juego, por María Victoria Estrada, Edda Madrid-Malo, Luz Marina Gil. F.R.B., UNICEF Colombia, Bogotá, 2000; Los derechos de la niñez. Una visión integral en Digitalizado por RED ACADEMICA
} 
desarrollado un conjunto de cartillas para el desarrollo de habilidades para la resolución pacífica de conflictos ${ }^{53}$; también el Instituto Luis Carlos Galán ha desarrollado cartillas con fines semejantes ${ }^{54}$. La Secretaría de Bogota desarrolló pruebas de comprensión y sensibilidad ciudadana en 1998 para evaluar los conocimientos y la sensibilidad de los estudiantes que son útiles para conocer variación entre escuelas, y para promover discusión entre equipos docentes en una escuela en relación a cómo desarrollar estas disposiciones y conocimientos. Las Escuelas de Perdón y Reconciliación, en varios barrios de Bogotá, también han adquirido experiencia valiosa en el desarrollo de metodologías para promover la no-violencia.

Ejemplos de sitios en la red donde hay catálogos de materiales para enseñanza de habilidades para la vida en democracia y para la resolución pacífica de conflictos desarrollados en otras latitudes son:

Civitas International, www.civnet.org

International Bureau of Education, ww.ibe.unesco.org/regional/diversity

Center for Social and Emotional Learning, www.csee.net

Character Education Partnership, www.character.org

Creative Responses to Conflict, www.ccrcglobal.org

Facing History and Ourselves, www.facinghistory.org

Human Rights Education Association, www.hrea.org

Fund for Global Awakening, www.ffga.org

Peace Games, www.peacegames.org

Resolving Conflict Creatively, www.esrnational.org

Seeds of Peace, www.seedsofpeace.org

Voices of Love and Freedom, www.naschools.org

Workable Peace, www.workablepeace.org

La tarea de desarrollar competencias cívicas en la escuela debe ser apoyada por acciones complementarias fuera de la escuela. Esto significa varias cosas interrelacionadas. En primer lugar, que el diálogo sobre los propósitos a que ha de servir la educación, ha de ser un diálogo abierto a la participación de la ciudadanía. Las políticas educativas han de ser concebidas reflejando la pluralidad de intereses legítimos en una sociedad moderna. En particular, es necesario identificar y desarrollar mecanismos para

procesos de atención, por Nelson Ortiz Pinilla. F.R.B., UNICEF Colombia, 1997; La dimensión ético de los proyectos sociales el sentido, por Esmeralda Ruiz González, ICBF, F.R.B., Fundación FES, UNICEF Colombia, Bogotá, 2001; Familia y Comunidad. En el marco de la protección integral, por Catalina Turbay Restrepo. F.R.B., UNICEF Colombia, Diciembre, Bogotá, 1997; Niña azul niño rosa. Reflexiones sobre el enfoque de género en el proceso de formación de niñas y niños, por Mónica Tobón Coral. F.R.B., UNICEF Colombia, I.C.B.F., Fundación FES, Abril, Bogotá, 2001; Régimen jurídico para instituciones de protección, por Faridy Jiménez Valencia y Gloria Elena Ochoa. Instituto SER de Investigación, F.R.B., Mayo, Bogotá, 1997; Elementos conceptuales básicos. Manual para facilitadores y formadoras, por Gloria Elena Ochoa y Maribel Delgadillo. Instituto SER de Investigación, F.R.B., Junio, Bogotá, 1997; La información. Estrategia para el crecimiento de la organización, por María Victoria Estrada y Carmenza González de Arenas. Fundación Rafael Pombo, F.R.B., Junio, Bogotá, 1997; Una mirada a las niñas en las instituciones de protección, por Paulina Ospina Mallarino. UNICEF Colombia, F.R.B., Diciembre, Bogotá, 1997. Para mas información véase www.funrestrepobarco.org.co

53 Programa por la Paz. Compañía de Jesús. Proceso de formación. Desarrollo de habilidades para la construcción de la paz. Cartillas 1, 2 y 3. propazsj@unete.com

${ }_{54}$ Resolución democrática de los conflictos en la escuela, por Rodrigo Uprimny, Guido A. Bonilla, Juan G. Gómez. Instituto para el desarrollo de la democracia Luis Carlos Galán, UNICEF Colombia, Febrero, Bogotá, 1998, sdc@ilcg.colnodo.apc.org 
que los más pobres puedan participar en expresar sus preferencias en relación a qué propósitos pretenden para la educación de sus hijos. Sería estupendo que los grupos locales de investigación que están apoyando el diálogo de la Alianza, entrevistaran a grupos de padres de familia, a desertores escolares y a estudiantes, para conocer qué esperan ellos de la escuela, qué destrezas y habilidades quieren aprender, en qué medida lo que se aprende en la escuela es pertinente a las necesidades que ellos tienen. El diseño y la implementación de las políticas educativas han de ser oportunidades cotidianas para desarrollar competencias de negociación, de reconocimiento de intereses diversos, de identificación de oportunidades de mutuo beneficio, de aprender a confiar en los demás a través de experiencias compartidas, de resolver pacífica y productivamente diferencias en el desarrollo de proyectos concretos para actualizar el potencial de todas las personas.

En segundo lugar, es necesario que la administración de los sistemas educativos esté abierta al escrutinio público. Esto implica también el desarrollo de formas de colaboración con organizaciones de la sociedad civil, con organizaciones no gubernamentales, asociadas con las escuelas públicas en el mejoramiento de la oferta educativa. También desarrollar formas de participación de la comunidad en la gestión educativa, más como forma de desarrollar capital social a nivel local que como estrategia para mejorar la efectividad pedagógica de los centros.

El carácter centralista de muchas decisiones de política educativa, pesado legado de la larga herencia autoritaria de América Latina, y la ausencia de una cultura de evaluación pública de los resultados de las políticas educativas, cercenan la posibilidad de construir una agenda pública -la cual debería ser el resultado de un modelo pluralista de negociación entre intereses en competencia- en la que estén representados los intereses de los beneficiarios de la educación y en particular los de los más pobres.

Pero para que estas ideas sean verdaderamente públicas, para que no sean dominio particular de grupos limitados de funcionarios educativos, es esencial que las mismas se inserten en procesos de discusión pública, de diálogo democrático, que contribuyan a hacer al público cada vez más sofisticado en su conocimiento y comprensión de los problemas educativos, así como de las opciones para intervenir sobre estos problemas.

Para concluir, admiro la tarea en la que están ustedes comprometidos de mejorar la equidad y la competitividad a través de mejorar la educación pública. Creo que esa meta es posible de alcanzar y que como resultado de los procesos de cambio que están ustedes apoyando podremos ver pronto en Antioquia, Santander, Medellín, Cartagena, Pasto, Caldas y Cundinamarca, escuelas públicas que sean el equivalente a las bibliotecas públicas construidas en barrios populares en Bogotá hace unos años. Lo más importante de estas escuelas excelentes será no su infraestructura física, aunque esto tiene valor simbólico, sino que en estas escuelas los profesores se sentirán orgullosos de serlo porque sabrán que son tratados como profesionales y que sobre ellos hay muy altas expectativas en relación a la tarea de formar ciudadanos y de construir una verdadera cultura de paz. Estos profesores y los directores en las escuelas trabajarán colegiadamente, demostrando a sus estudiantes lo que es el trato respetuoso y el trabajo productivo en equipo, se comunicarán productivamente, construirán fuertes culturas escolares en las que haya altas expectativas sobre la capacidad de que todos los estudiantes aprendan a niveles de profundidad contenidos y habilidades que les hagan libres y capaces de vivir en paz con los demás. Como el resultado de este trabajo colegiado de autoformación, de los materiales de excelente calidad con que contarán ellos y sus alumnos y del apoyo técnico que recibirán para desarrollar sus capacidades 
profesionales de amigos críticos y especialistas de otras instituciones locales, estos maestros serán mucho más competentes de lo que son hoy en día para enseñar a sus estudiantes de forma efectiva. Estos maestros tendrán relaciones respetuosas y efectivas de comunicación con los padres de familia, y como resultado de ello los maestros conocerán mejor a cada estudiante, pudiendo enseñarle aún mejor, y los padres de familia podrán apoyar más efectivamente el trabajo académico de los estudiantes. Tanto los maestros, como la comunidad en su conjunto entenderán la importancia de que los estudiantes, niños y jóvenes, estén en la escuela, estudiando, haciendo deporte, en las bibliotecas, pero sobre todo que no estén en las calles o participando en actividades ilegales. Para ello, habrá sistemas de detección temprana del riesgo de la deserción, los maestros preguntarán al término de cada curso cuáles alumnos piensan volver al año siguiente, y movilizaran a personal de la escuela y de otras instituciones de la comunidad para apoyar a aquellos jóvenes en riesgo de abandono de la escuela. Estos resultados serán posibles por el esfuerzo coordinado de diversos grupos en cada comunidad, y en cada estado, apoyado por conocimiento específico generado por instituciones locales de investigación que generen conocimiento sobre las condiciones de trabajo en las escuelas, sobre los factores asociados al aprendizaje de los estudiantes, sobre las razones de la deserción escolar, y que traduzcan este conocimiento en productos utilizables para apoyar procesos de mejoramiento de las escuelas. Sé que alcanzar estos resultados es posible y confío en que al hacerlo habrán ustedes contribuido a consolidar las condiciones para una paz duradera en Colombia. 